\title{
LA TRADICIÓN DE ARTE CHAMÁNICO SHIPIBO-CONIBO (AMAZONÍA PERUANA) Y SU RELACIÓN CON LA CULTURA DIAGUITA CHILENA
}

\author{
SHIPIBO-CONIBO SHAMANIC ART OF THE PERUVIAN AMAZON AND \\ ITS RELATION TO THE DIAGUITA CULTURE OF CHILE
}

\author{
PaOla González
}

El arte diaguita preincaico presenta una lógica visual caracterizada por el empleo de complejas simetrías, ilusión de movimiento y vibración, infinita variabilidad a partir de elementos geométricos acotados, horror vacui, atracción hipnótica, entre otros. Estas características, así como la asociación de este arte a un alter ego animal (jaguar) y la evidencia de consumo de alucinógenos, permiten plantear un vínculo cultural con cierto arte visual de naturaleza arqueológica (mojocoya) y etnográfica (shipiboconibo). Planteamos que, en este caso, se trata de "tecnologías de encantamiento" (Gell 1998) que tienen agencia y cautivan al espectador, pues los patrones abstractos poseen características de animación no mimética de difícil comprensión. En contextos etnográficos, estos patrones decorativos cumplen un importante rol en estrategias de sanación chamánicas.

Palabras clave: cultura Diaguita chilena, cultura ShipiboConibo, arte chamánico sudamericano, simetría, vínculos culturales.

Pre-Inca Diaguita decorative patterns present a visual logic, characterized by the use of complex symmetries, optical illusions, an endless variety of simple geometric forms, horror vacui, hypnotic attraction and other techniques. These aspects, as well as the association of this visual art with an animal alter ego (jaguar) and evidence of the use of hallucinogenics, suggest a cultural link with specific ethnographic (shipibo-conibo) and archaeological (mojocoya) visual art. We propose that in this case we are dealing with visual "technologies of enchantment" (Gell 1998) that are deemed to have social agency and captivate the viewer with extremely complex, apparently animated non-mimetic abstract patterns. In ethnographic contexts, similar decorative patterns play an important role in shamanic healing strategies.

Keywords: Diaguita Culture, Shipibo-Conibo Culture, South American Shamanic Art, Symmetry, Cultural Linkages.

\section{INTRODUCCIÓN}

La cultura Diaguita chilena creó un estilo de representación abstracto y simétrico cuyos simbolismo y contexto recién en nuestros días hemos logrado descubrir en parte. $\mathrm{El}$ arte abstracto es esencialmente ambiguo, vale decir, el observador no puede asignar un contenido unívoco a las representaciones. El arte diaguita preincaico explora juegos ópticos que engañan nuestra percepción; se trata de configuraciones visuales en que "formas y esquemas puros tienden a transformarse ante nuestros ojos. Casi parece como si el ojo conociera sentidos de los que la mente no sabe nada. La yuxtaposición de formas y colores nos hace caer en las más inesperadas trampas, las trampas conocidas como 'ilusiones ópticas"' (Gombrich 1999: 260).

La maestría y delicadeza de sus diseños da cuenta de la importancia cultural asignada a esta actividad por sus creadores. Sin embargo, comprendemos solo parcialmente lo que subyace a este marcado esfuerzo cultural por explorar los derroteros del arte abstracto y simétrico. Es importante, entonces, realizar un esfuerzo por acercarnos a este concepto indígena de lo estético.

Por otra parte, planteamos que el arte diaguita preincaico no constituye un logro aislado en el contexto indígena sudamericano, sino que forma parte de una tradición cultural mayor, que cuenta con una gran profundidad temporal y de la cual aún existen pueblos 
indígenas que la practican y reactualizan, en distintas regiones de Sudamérica. En el presente trabajo, propongo dar una mirada más profunda a las vinculaciones culturales entre la cultura Diaguita chilena preincaica y la cultura etnográfica Shipibo-Conibo de la Amazonía peruana, a partir de la identificación de características comunes entre ambas iconografías. Para ello, adopto un punto de vista estructural y simbólico que también considera el contexto cultural de estas manifestaciones artísticas. De igual modo, examino antecedentes arqueológicos de la cultura Shipibo-Conibo, específicamente referidos a la cultura Cumancaya (Lathrap 1970) y la posible existencia de un ancestro común entre esta cultura y la cultura Diaguita (cultura Mojocoya).

Para la cosmovisión shipibo-conibo, los diseños realizados sobre un soporte material -ya sea piel, cerámica, tela o madera- ponen de manifiesto los diseños inmateriales observados en las visiones nacidas de la ingesta de ayahuasca, y tienen un gran poder curativo. Este complejo concepto de arte entrega claves para el desarrollo de caminos interpretativos del arte diaguita preincaico; asimismo, la previa comprensión y sistematización del arte diaguita, desde una perspectiva estructural y cronológica (González 2013), nos deja en un mejor pie para estudiar esta tradición de arte visual en tiempos etnográficos.

\section{ALGUNAS PRECISIONES SOBRE EL CON- CEPTO DE ARTE CHAMÁNICO INDIIGENA EN SUDAMÉRICA}

Reichel-Dolmatoff (1985) ha dado luces acerca de una clase específica de arte visual sudamericano presente en contextos etnográficos y vinculado con prácticas chamánicas. Este nos interesa como concepto, dado que presenta una gran semejanza con el arte diaguita preincaico, que comprende tanto el ámbito gráfico en sí como también otras esferas de actividad y prácticas culturales. En 1985, Reichel-Dolmatoff destacaba que

uno de los descubrimientos más importantes en las últimas décadas, en el campo de la etnología, consiste en la confirmación de que el arte y las religiones chamanísticas se relacionan estrechamente con el uso de drogas alucinógenas [...] la ingestión de drogas alucinógenas representa el mecanismo principal de inducir estados visionarios chamanísticos, acompañados de la ilusión de viajar por los aires, de transformarse en un animal y de penetrar en otras dimensiones cósmicas, fuera de esta tierra (1985: 292).
De acuerdo con el autor, los motivos geométricos utilizados en estas representaciones (por ejemplo, estrellas, puntos o líneas) cuentan con una base neurofisiológica, reflejan fosfenos: "sensaciones luminosas que aparecen en el campo de visión, independientemente de una luz externa, es decir, son producto de la autoiluminación del campo visual y se producen en el cerebro" (1985: 293). Destacamos que dichos motivos geométricos presentan una marcada simetría bilateral.

De este modo, tomando como punto de partida la naturaleza y estructura simétrica del arte visual diaguita preincaico y su contexto cultural, así como las semejanzas con otros estilos de arte visual etnográfico sudamericano vinculados con religiones chamánicas, especialmente amazónicos -como los tukano (ReichelDolmatoff 1985), shipibo-conibo (Gehbart-Sayer 1985) y caduveo (Lévi-Strauss 1992 [1955])-, he planteado la existencia de un conjunto de caracteres comunes a todos ellos (González 2006, 2013). Estas características comunes, tanto contextuales como de estilo, sugieren la existencia de una tradición estilística compartida que relaciona arte visual abstracto y simétrico, ingesta de psicoactivos y prácticas chamánicas, tradición que estaría presente en un conjunto de culturas sudamericanas específicas, tanto de tiempos arqueológicos como de tiempos etnográficos.

\section{VINCULACIONES ENTRE EL ARTE DIAGUITA PREINCAICO Y EL ARTE SHIPIBO-CONIBO}

En los párrafos siguientes, exploraremos los caracteres comunes entre la cultura Diaguita preincaica y la cultura Shipibo-Conibo. Se distinguirá entre aspectos externos que rodean sus prácticas sociales y creencias en torno al arte, propias de su contexto cultural, por una parte, y las características intrínsecas del arte visual que son comunes a ambos pueblos, desde un punto de vista simbólico y estructural, por otra.

\section{Aspectos externos o contexto cultural común del arte visual de ambas culturas}

\section{Asociación del arte visual a un alter ego animal}

En la iconografía diaguita, la imagen del felino moteado es un símbolo que antecede a la llegada de los incas a su territorio. Esta se registra desde la fase Diaguita II 


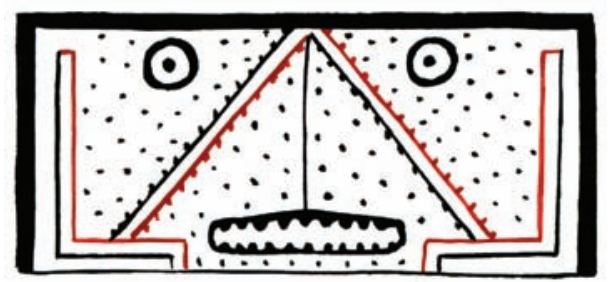

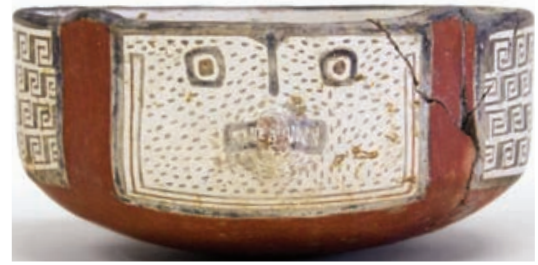

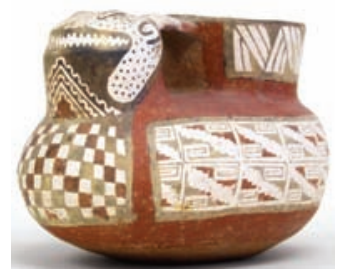

Figura 1: a) diseño central escudilla zoomorfa; b) escudilla zoomorfa, colección Museo del Limarí; c) Jarro Pato, Museo del Limarí, $\mathrm{N}^{\circ}$ Inventario 1280. Figure 1: a) central design on zoomorphic serving dish; b) zoomorphic serving dish, Museo del Limarí collection; c) Duck-shaped pitcher, Museo del Limarí. Inventory \# 1280.

(1200-1470 DC) e informa sobre el sistema de creencias de aquella población en periodos previos a su integración al Imperio Incaico. Se la puede encontrar en en jarros pato, vasos dobles, escudillas zoomorfas y espátulas destinadas al consumo de alucinógenos.

Creemos que es posible establecer una relación entre la imaginería del felino y las prácticas chamánicas ligadas al consumo de psicoactivos en la cultura Diaguita. En este sentido, Troncoso (2005) analiza el plato zoomorfo/antropomorfo diaguita, que presenta en su diseño central la representación de un felino moteado con características antropomorfas. El autor plantea que el arte visual diaguita presenta relaciones con prácticas chamánicas, rasgo común con otras sociedades andinas. Con respecto a la escudilla zoomorfa/antropomorfa, indica que la organización de la decoración de esta vasija da cuenta de un principio andino básico, consistente en conceptualizar el espacio dividiéndolo en dos mitades y con un centro (chamán), mediador entre opuestos (fig. $1 \mathrm{a}-\mathrm{c}$ ).

Por otro lado, en la cultura Shipibo-Conibo la anaconda es el animal tutelar esencial, que se vincula estrechamente con la generación de su complejo arte visual (fig. 2a). Gehbart-Sayer (1985: 147) se refiere al culto de la deidad tutelar Ronin (Gran boa), señalando: "Este ser es el dador mítico de los diseños, esta serpiente concentra todos los diseños concebibles en su piel [...] Ronin rau es también la designación simbólica de la ya mencionada terapia chamánica en la cual el chamán sana a su paciente a través de la aplicación de los diseños visionarios". Ronin también se expresa en un diseño abstracto (fig. 2b).

Illius, por su parte, aporta un interesante dato en relación a la importancia simbólica del jaguar entre los shipibos: cuando un chamán llega al más alto nivel de maestría, es llamado meraya, es decir, "el que se transforma en jaguar” (Illius 1991-1992: 197).

\section{Consumo de alucinógenos}

En el norte semiárido chileno, el consumo de alucinógenos se registra desde el complejo El Molle (Castillo 1992). La práctica se generaliza durante el complejo Ánimas y es continuada en la cultura Diaguita, incluyendo el periodo de contacto Inca. Destacamos que los símbolos del jaguar y el sacrificador se representan en

a

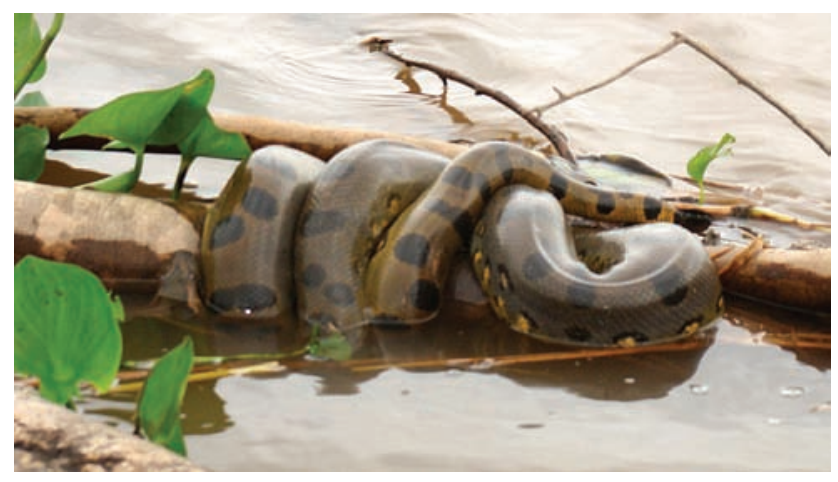

b

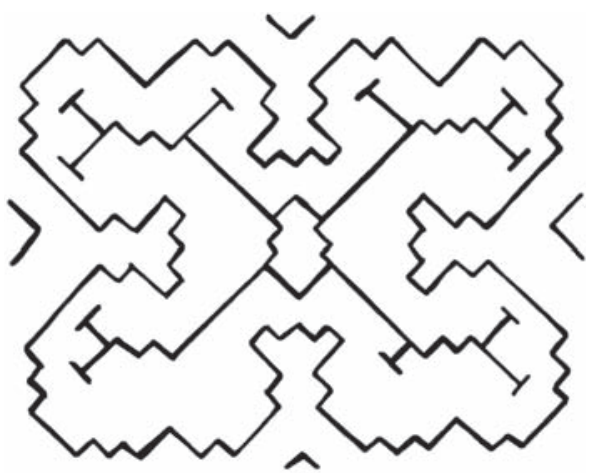

Figura 2: a) anaconda, Ucayali central (fotografía de Paola González); b) diseño de anaconda (Gehbart-Sayer 1985: 150). Figure 2: a) anaconda, Ucayali central (photo by Paola González); b) anaconda design (Gehbart-Sayer 1985: 150). 


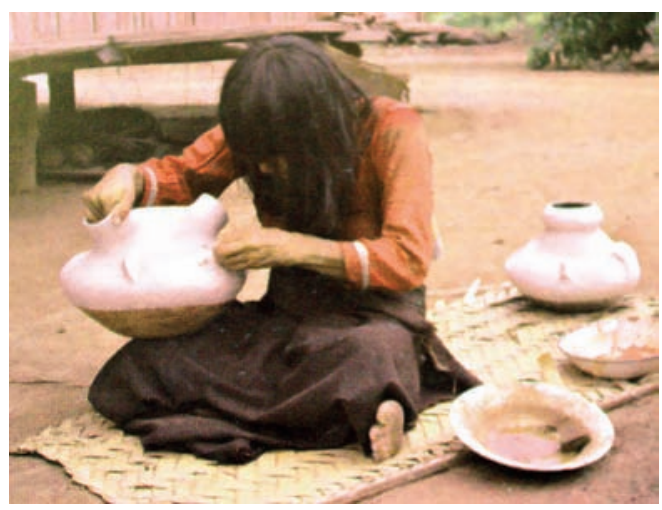

b

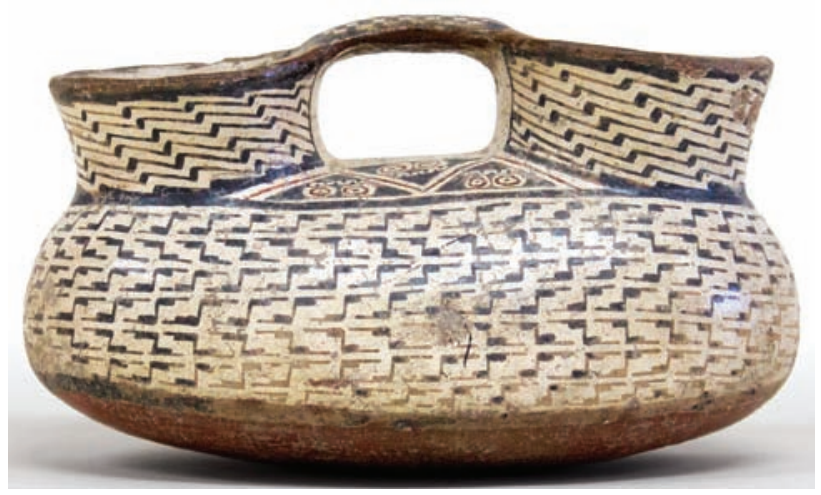

Figura 3: a) artesana shipibo (Instituto Cultural Peruano Norteamericano 2002: 39); b) jarro Pato diaguita, Museo del Limarí, $\mathrm{N}^{\circ}$ Inventario 31. Figure 3: a) Shipibo craftswoman (Instituto Cultural Peruano Norteamericano 2002: 39); b) diaguita duck-shaped pitcher, Museo del Limarí, Inventory \# 31.

las espátulas utilizadas en el consumo de psicoactivos. Las evidencias materiales del consumo de alucinógenos en las culturas Ánimas y Diaguita considera la presencia de tubos, espátulas y conchas de ostión, que en estos contextos reemplazan a las tabletas. No ha sido posible, hasta el momento, identificar la sustancia psicoactiva consumida.

En tanto, en la cultura Shipibo-Conibo los patrones de diseño son percibidos por el chamán o por las mujeres diseñadoras mediante el consumo de ayahuasca y poseen un gran poder curativo. Al respecto, GehbartSayer señala que a través del consumo de ayahuasca los chamanes obtienen visiones fosfénicas que "cubren todo el espacio de la visión del chamán. Con la asistencia de sus espíritus auxiliadores, el chamán comienza a interpretar las visiones como un diseño medicinal quiquin. Tan pronto como la red flotante toca sus labios el chamán entona melodías que corresponden a las visiones luminosas" (1985: 171). Illius (1991-1992: 23) explica que la ayahuasca "produce no solamente alucinaciones auditivas, sino en primer lugar (y en todos los que la utilizan) alucinaciones visuales. El que se halla bajo los efectos de la misma ve personas, animales, plantas, seres anómalos, paisajes y figuras abstractas en gran número y rápida sucesión" (1991-1992: 26).

Otros aspectos culturales comunes entre diaguitas y shipibo-conibos

Por una parte, se trata de comunidades sedentarias y agricultoras, ambos pueblos se caracterizan por ser grandes ceramistas que manejan una elaborada iconografía de naturaleza abstracta y simétrica (fig. 3 a). En el caso de la decoración cerámica, esta se efectúa tanto entre diaguitas como entre shipibos a través de pintura polícroma en blanco, negro y rojo. Coincidentemente, unos y otros excluyen de manera deliberada la decoración del sector de la base.

Es interesante detenernos un poco en el último rasgo común a ambos estilos de decoración cerámica (fig. 3b). En la cultura Shipibo, esto se debe a que las vasijas cerámicas se organizan como un microcosmos (Illius 1991-1992: 28,30). Illius basa esta afirmación en el testimonio del chamán shipibo Barin Ramá y aclara la correlación existente entre patrones decorativos de la vasija para contener chicha (Chomo) y la cosmología chamánica shipibo. Asimismo, distingue en la vasija tres zonas claramente diferenciadas (1991-1992: 28-30). La primera de ellas, localizada en el sector superior de la vasija, corresponde al mundo superior o nete shama. Se trata de la región más elevada del cosmos, decorada por los diseños más finos, birish mayá quene (diseños finos y curvilíneos), complejamente entrelazados entre sí y con gran cantidad de bero multicolores. El autor informa que el mundo superior nai se halla sostenido y limitado por una imponente canoa, palabra que significa tanto un determinado tipo de diseño como también "enrejado" o "andamio". Alcanzar esta zona del cosmos es el objetivo del viaje del shamán. En la parte media de la vasija se encuentra el mundo intermedio mai (tierra), la "realidad diaria", que posee diseños de calidad común. Finalmente, en el sector inferior de este ceramio se distingue el mundo subterráneo (jene), de naturaleza acuática, que carece de diseños (quené-oma).

Otros elementos culturales detectados en ambos pueblos son el entierro en urnas y la práctica de de- 
a

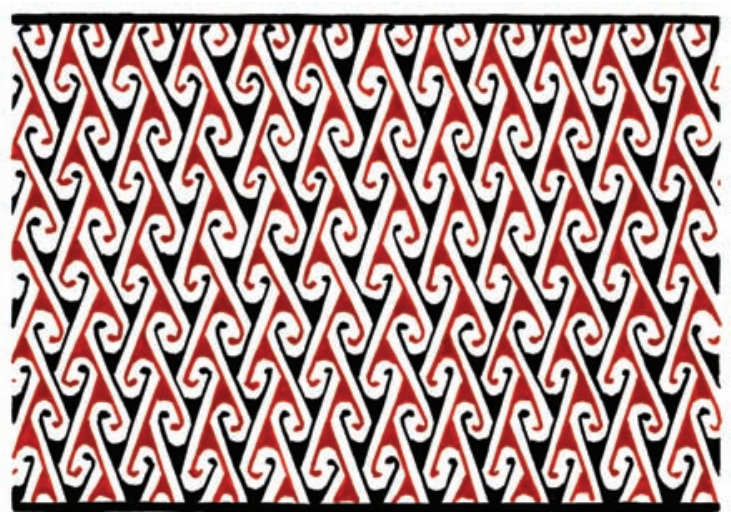

b

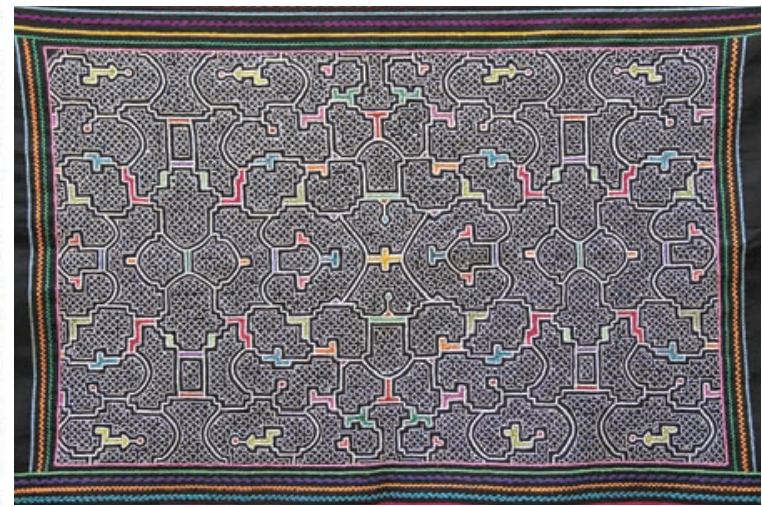

Figura 4. Simetría Compleja: a) diseño diaguita patrón Ondas C9 (González 2013: 112); b) textil shipibo, comunidad Panaillo (fotografía de Paola González). Figure 4. Complex symmetry: a) Diaguita C9 wave pattern (González 2013: 112); b) Shipibo textile, Panaillo community (photo by Paola González).

a

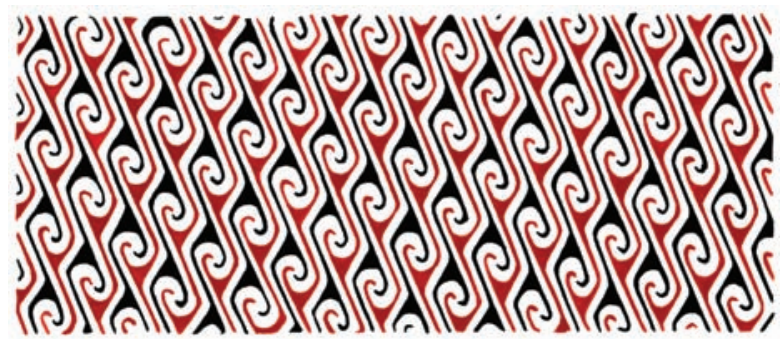

b

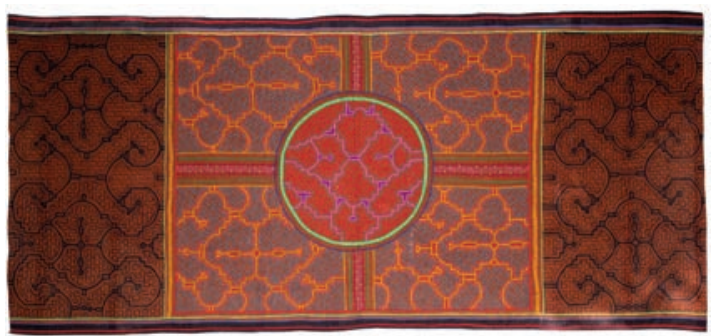

Figura 5. Horror Vacui: a) patrón diaguita Ondas E4 (González 2013: 117); b) textil shipibo, comunidad de Panaillo (fotografía de Paola González). Figure 5. Horror Vacui: a) diaguita E4 wave pattern (González 2013: 117); b) Shipibo textile, Panaillo community (photo by Paola González).

formación craneana. Morales Chocano (2002) agrega otras características comunes entre los shipibos y un conjunto de pueblos amazónicos, que también están presentes en los diaguitas. Por ejemplo, simetría bilateral en sus diseños cerámicos, uso de espirales escalonadas insertas en rectángulos, urnas con rasgos zoomorfos y antropomorfos, entre otras.

Características intrínsecas del arte visual compartidas por la cultura Diaguita y la cultura Shipibo-Conibo

Los paralelos más interesantes entre el arte visual shipibo-conibo y el diaguita preincaico se observan al considerar las características intrínsecas de su arte visual, que revisamos a continuación.

\section{Simetría compleja}

Tanto el arte shipibo como el arte visual de la cultura Diaguita de origen preincaico se caracterizan por poseer una compleja simetría, que utiliza dos o más principios conjuntamente; por ejemplo, rotación y reflexión. En ambos universos representacionales se observa un manejo avezado de los principios de simetría (traslación, reflexión en espejo, reflexión desplazada y rotación) (fig. 4 a, b).

\section{Horror vacui}

Ambos universos representacionales se caracterizan por el esfuerzo del artesano por llenar minuciosamente todo el espacio disponible en el campo del diseño. Mediante unidades mínimas abstractas y un orden simétrico preestablecido se repite la unidad mínima hasta completar toda la superficie a decorar (fig. 5 a, b).

\section{Contracambio o visión en positivo/negativo}

Tanto en el arte shipibo como en el arte diaguita preincaico encontramos numerosos diseños que permiten una doble lectura entre figura y fondo, al punto que es posible alternar la interpretación del diseño entre una y 

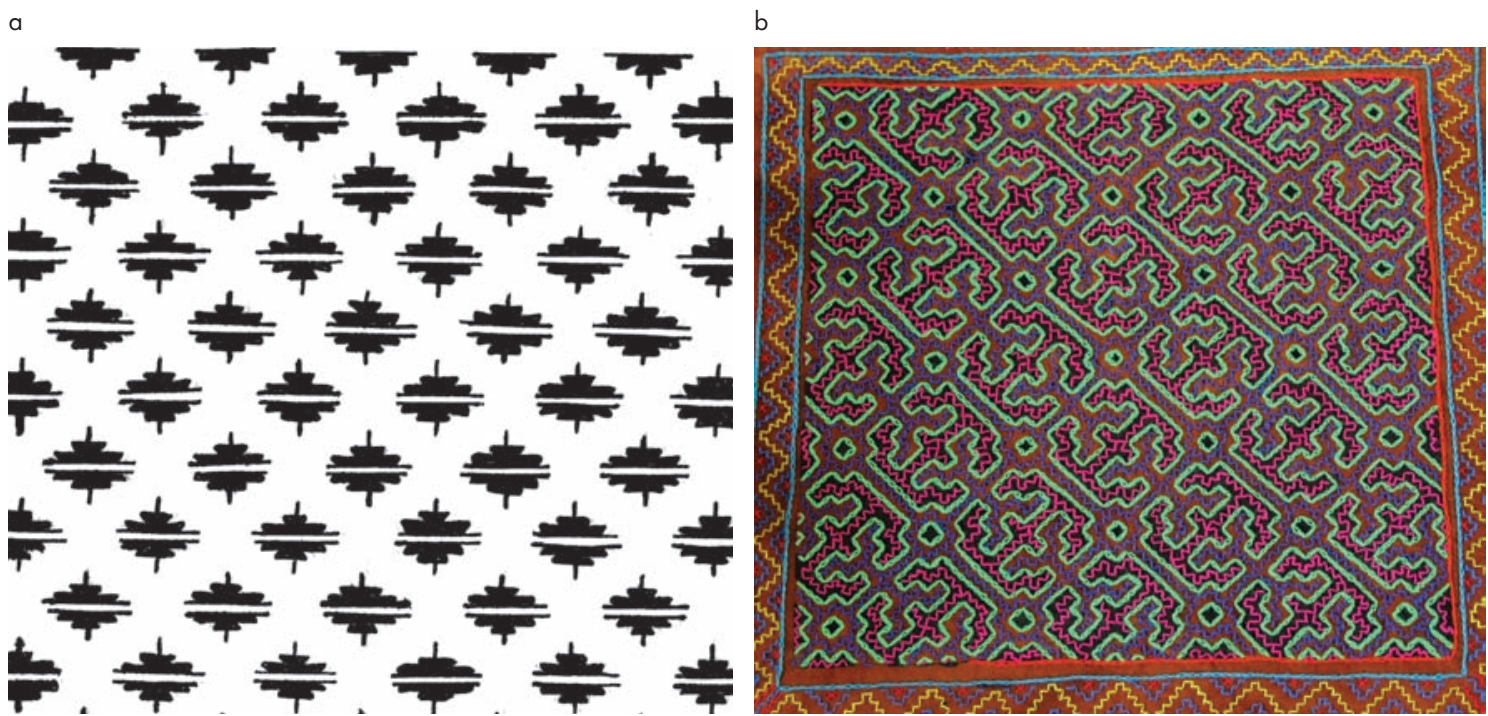

Figura 6. Visión en positivo/negativo: a) patrón diaguita Escalonados en reflexión A (González 2013: 149); b) textil Shipibo (colección Paola González). Figure 6. Positive/negative designs: a) Diaguita stepped motifs, reflection A (González 2013: 149); b) Shipibo textile (Paola González collection).

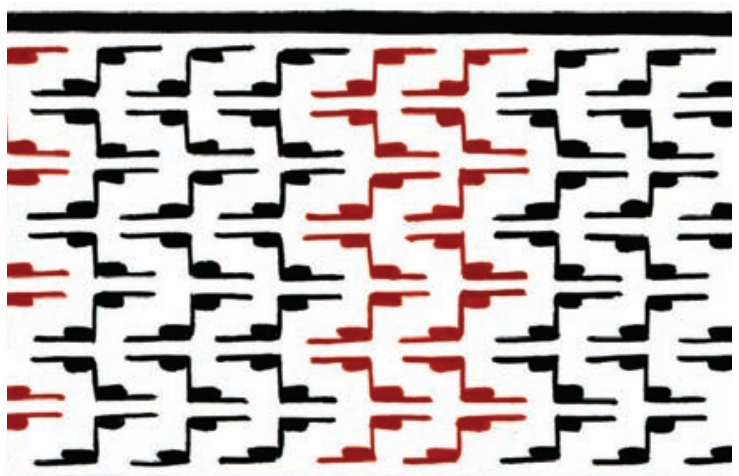

b

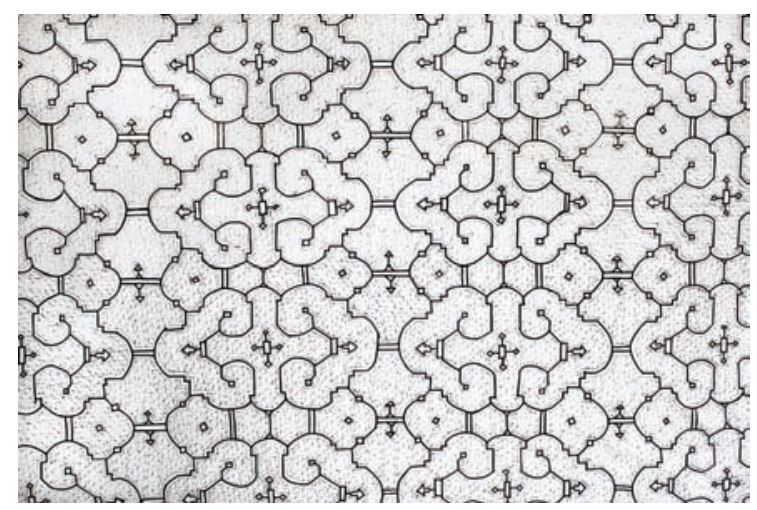

Figura 7: a) patrón diaguita Líneas quebradas C3 (González 2013: 146), Repetición periódica; b) textil shipibo comunidad Paoyan (colección Paola González). Figure 7: a) Diaguita C3 broken line pattern (González 2013: 146), Regular repetition; b) Shipibo textile, Paoyan community (Paola González collection).

otra. En el arte islámico encontramos grandes ejemplos de esta técnica: el artesano persigue crear juegos ópticos que desafíen los umbrales de nuestra percepción visual (fig. 6 a, b).

\section{Repetición periódica}

Consiste en la elaboración de unidades mínimas y estructuras simétricas que se repiten periódicamente. En estas series de agrupaciones siempre hay una secuencia que se reitera. Existe una periodicidad a partir de un punto de referencia. Se observa una sucesión medida en series, como una moldura, una suerte de letanía o ritmo visual. Estos diseños presentan ciertas unidades congruentes consigo mismas que se combinan en una sucesión recurrente y se rigen por determinados principios simétricos (fig. 7 a, b).

Continuación sin fin o poder autogenerador de los diseños

Se refiere a la capacidad que poseen estos diseños de extenderse más allá de su campo, en virtud de la repetición rítmica de los movimientos simétricos. El 
a

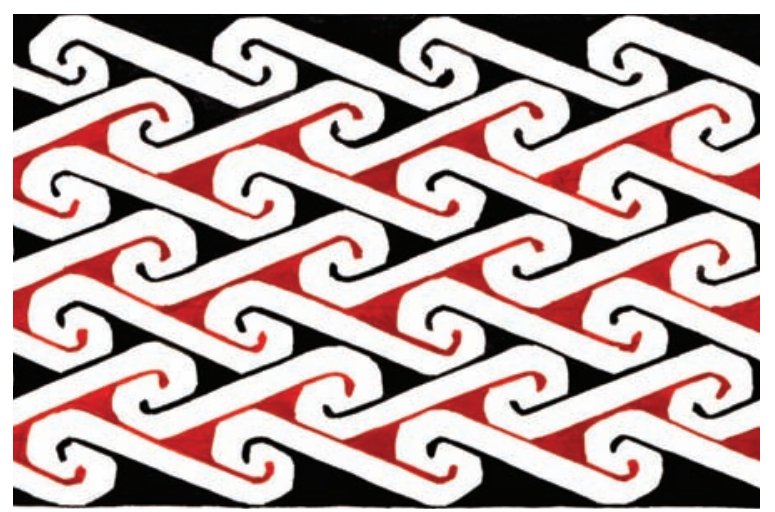

b

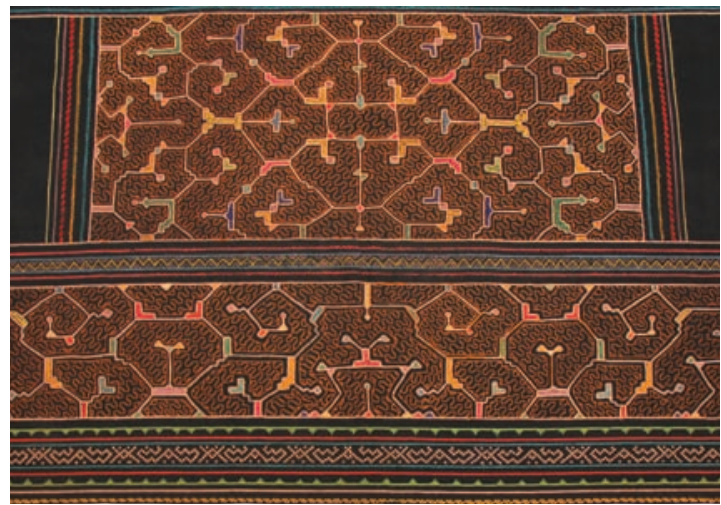

Figura 8. Continuación sin fin: a) patrón diaguita Ondas C3 (González 2013: 111); b) textil shipibo comunidad de Panaillo (colección Paola González). Figure 8. Continuous invariable patterns: a) Diaguita C3 wave pattern (González 2013: 111); b) Shipibo textile, Panaillo community (Paola González collection).

artesano secciona y delimita forzadamente el diseño en un espacio definido de la vasija decorada; no obstante, estas letanías visuales tienen la capacidad de autogenerarse y extenderse indefinidamente fuera del campo decorado (fig. 8 a, b).

\section{Amor infinito o interminable variabilidad a partir de unidades mínimas acotadas}

Esta propiedad fue definida por Heath (2002: 48) para el arte visual shipibo; sin embargo, es claramente aplicable también al arte diaguita preincaico. Se refiere a la búsqueda incesante de variabilidad a partir de elementos acotados, usando como motor de variabilidad la creación de leves cambios en las unidades mínimas, el patrón cromático y la estructura simétrica. Los patrones decorativos y sus variantes y subvariantes son iguales en un aspecto y diferentes en otro. No hay un límite para el desarrollo exponencial de variabilidad. Gombrich (1999) señala, en este sentido, que todo dibujo simétrico es siempre susceptible de variaciones posteriores mediante la creación de nuevos vínculos entre sus elementos constitutivos. Se trata de dispositivos para la exploración sistemática de posibilidades visuales, y operan como instrumentos para la expansión de invenciones por medio de permutaciones y combinaciones (fig. 9 a-f).

\section{Complicación gradual}

Se trata de la generación gradual de una rica red de progresiva complicación. De acuerdo a Gombrich (1999: 80), es propio de toda periodicidad geométrica el que pueda emplearse para generar nuevas periodicidades, en un proceso que define como "complicación gradual" y que está presente en la ornamentación de las artes visuales y de la música. Existe una retícula que enmarca y que es rellenada por un conjunto de motivos; ambos constituirían el ornamento. La coherencia de esta estructura está dada por la vinculación. El enmarcado o retícula delimita el campo y el relleno organiza el espacio resultante. En el arte diaguita podemos observar este proceso de complicación gradual en las sucesivas etapas que se observan en la construcción de un diseño. Primero, se elige una determinada unidad mínima; luego, esta unidad es dispuesta en una determinada retícula y ellas se vinculan entre sí por la acción de uno o más principios simétricos. En el caso ilustrado, vemos cómo la unidad mínima primero rota y se alinea en forma oblicua, y luego se refleja verticalmente, como un todo, formando un diseño triangular. Este diseño se traslada en sentido vertical y se refleja verticalmente hasta completar la banda, formando una línea zigzag (fig. 10 a-d).

En el arte shipibo-conibo, la lógica visual empleada en la génesis de los diseños es muy semejante. Por ejemplo, De Boer (1990: 90) explica que la cruz básica es diseñada primero. Este elemento se somete después a un número creciente de complejas operaciones que consideran concatenación, repetición y complejización -primero en una y luego en dos dimensiones-, y finalmente se somete a varias operaciones de partición y cambios de orientación. De acuerdo al autor, "el sentido de este patrón secuencial sugiere que un poderoso programa madurativo del tipo diagnosticado por Piaget (1970) está operando" (1990: 90). De Boer se refiere a la 

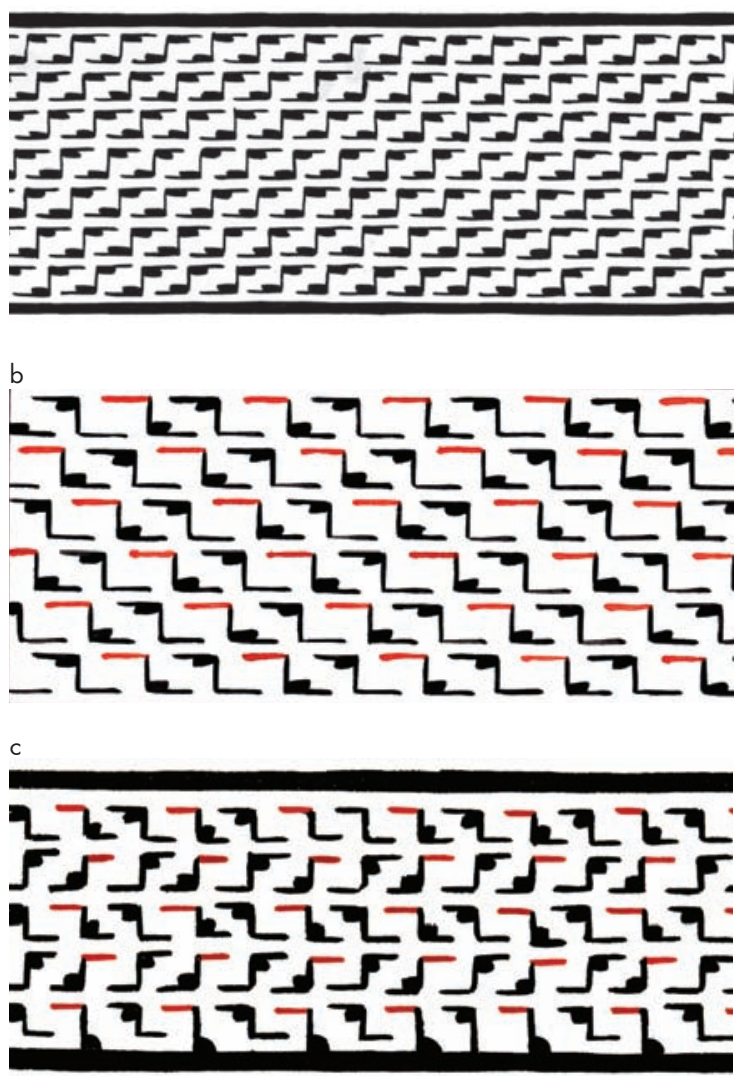

d
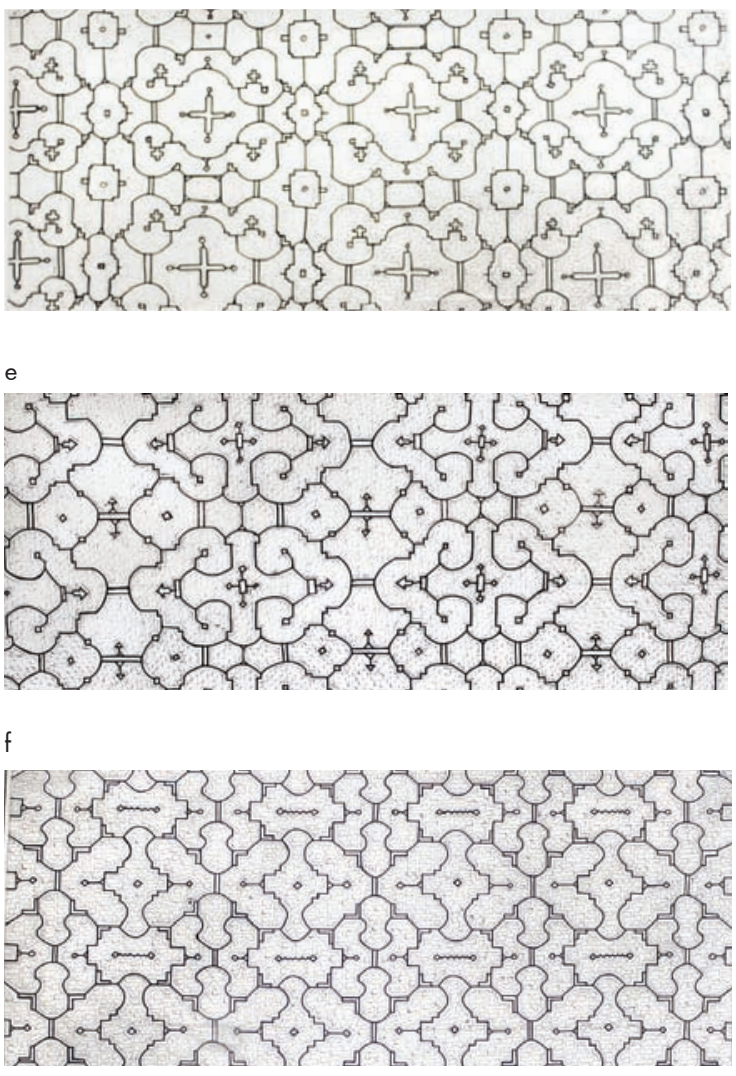

Figura 9. Interminable variabilidad: a) diseño diaguita Líneas quebradas A1 (González 2013: 143); b) diseño diaguita Líneas quebradas B2 (González 2013: 144); c) diseño diaguita,Líneas quebradas C2 (González 2013: 146); d) textil shipibo (colección Paola González); e) textil shipibo (colección Paola González); f) textil shipibo (colección Paola González). Figure 9. Continuous variable pattern: a) Diaguita A1 broken line design (González 2013: 143); b) Diaguita B2 broken line design (González 2013: 144); c) Diaguita C2 broken line design (González 2013: 146); d) Shipibo textile (Paola González collection); e) Shipibo textile (Paola González collection); f) Shipibo textile (Paola González collection).

ontogénesis del arte shipibo-conibo, señalando que se aprecia una derivación de motivos comunes a través de la división, a lo largo de un eje de simetría, que es seguido de nuevas reflexiones. Precisa que "ambas operaciones se basan en la simetría bilateral la cual es llamada por los shipibos como beibana quene, o literalmente, diseños 'cara a cara"' (1990: 88).

A modo de ejemplo, examinaremos cómo opera el principio de complicación gradual en un hermoso textil shipibo de la artesana Wilma García (comunidad de Panaillo). Este textil se encuentra regido por una doble reflexión especular, es decir, se trata de un diseño cuadripartito. La unidad mínima consiste en líneas curvas y pequeñas figuras rectilíneas, representada en la figura 11a. Este diseño sufre una reflexión horizontal, dando origen a la figura 11b. La composición así formada se refleja verticalmente, con lo que resulta la figura $11 \mathrm{c}$, que abarca la mitad del campo del diseño rectangular. Finalmente, este diseño se refleja horizontalmente, como un todo. Así se compone el diseño ilustrado en la figura d y se completa la decoración del campo del diseño. Dos ejes de simetría perpendiculares (cruz) gobiernan la totalidad de la composición (fig. 11d).

\section{Atracción casi hipnótica}

Esta propiedad se refiere a la capacidad que poseen estos diseños de favorecer una concentración profunda o un estado de consciencia alterado mediante la observación prolongada de sus imágenes, que generan una serie de efectos ópticos que engañan nuestra percepción visual (fig. $12 \mathrm{a}, \mathrm{b}$ ). 
a

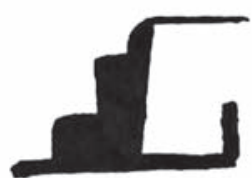

b

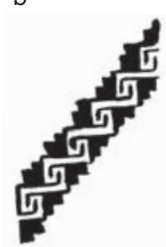

C

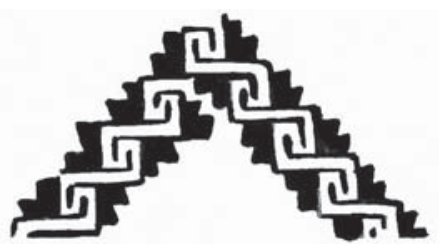

d

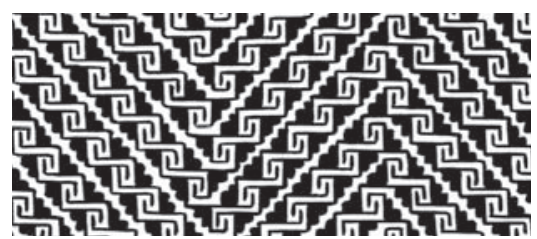

Figura 10. Complicación gradual diaguita: a) unidad mínima; b) rotación y alineación oblicua de unidad mínima; c) reflexión vertical de unidades mínimas alineadas; d) traslación horizontal y vertical de unidades alineadas y reflejadas (González 2013: 77 ). Figure 10. Diaguita gradual complexification: a) minimum unit; b) rotation and diagonal alignment of the minimum unit; $c$ ) vertical reflection of aligned minimal units; d) horizontal and vertical translation of aligned, reflected units (González 2013: 77).

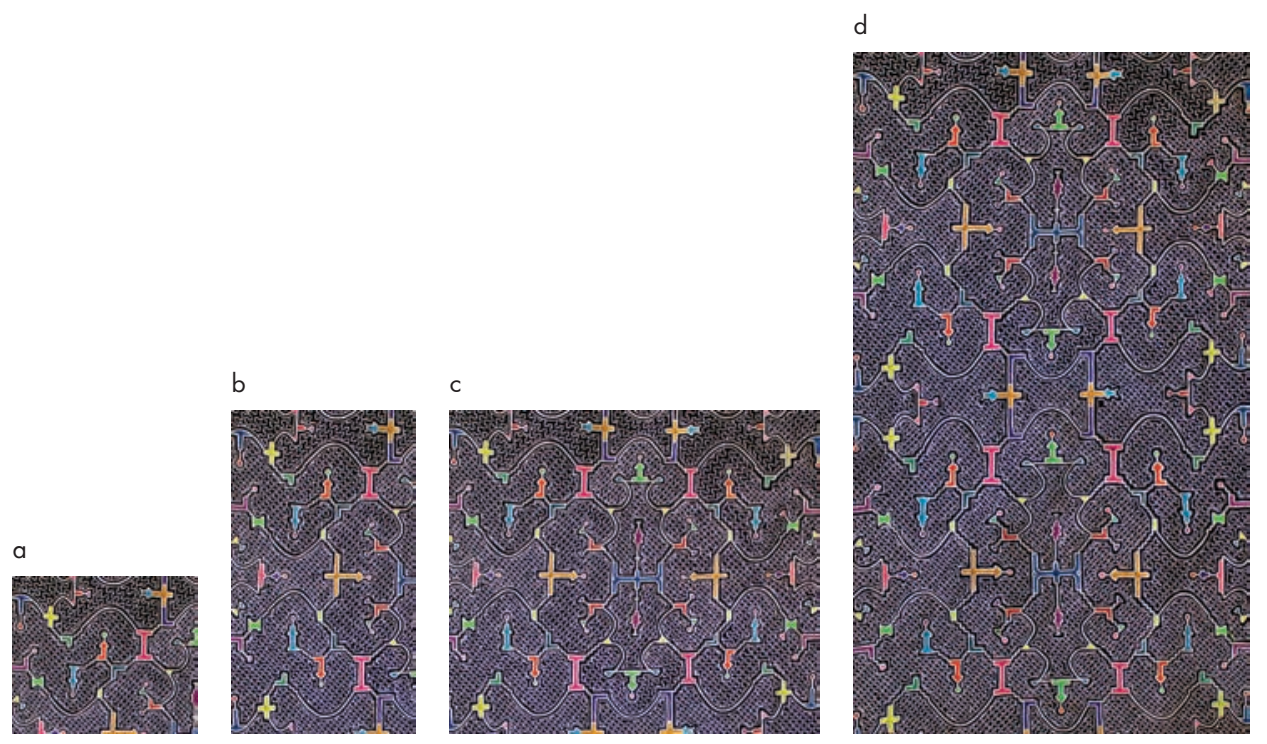

Figura 11. Complicación gradual shipibo. Figure 11. Shipibo gradual complexification.
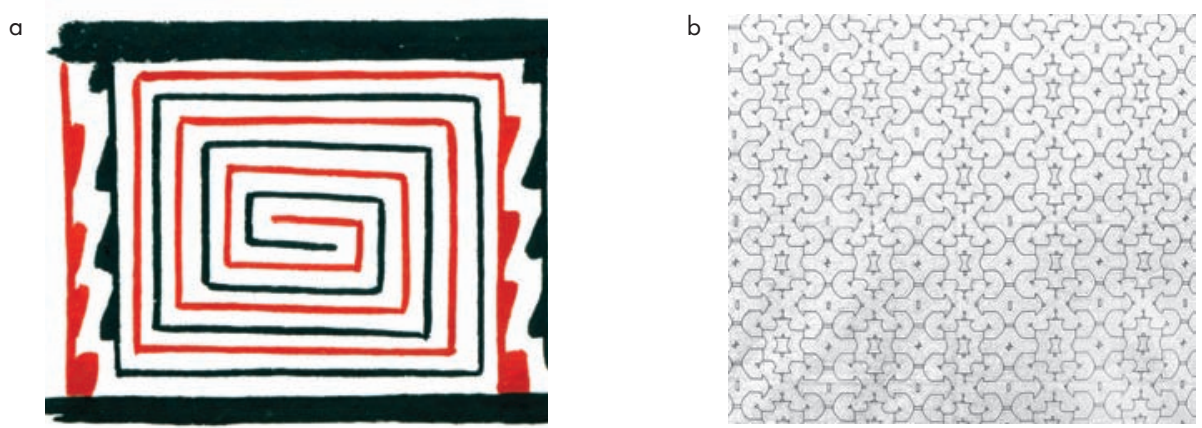

Figura 12. Atracción casi hipnótica: a) patrón diaguita Laberinto A2 (González 2013: 152); b) textil shipibo (colección Paola González). Figure 12. Nearly hypnotic attraction: a) diaguita A2 labyrinth pattern (González 2013: 152); b) Shipibo textile (Paola González collection).

Ilusión óptica de movimiento y vibración

En forma semejante al estilo moderno de arte óptico, en muchos diseños diaguita de origen preincaico y shipibo se aprecia el efecto óptico de movimiento y/o vibración a partir de diseños planos, estáticos y bidimensionales.
Se engaña al ojo, de modo que el cerebro interpreta que existe movimiento o vibración cuando realmente no hay tal. Este efecto se logra por medio del empleo repetitivo de formas geométricas simples articuladas por complejos movimientos simétricos y un marcado contraste cromático (fig. 13 a, b). 


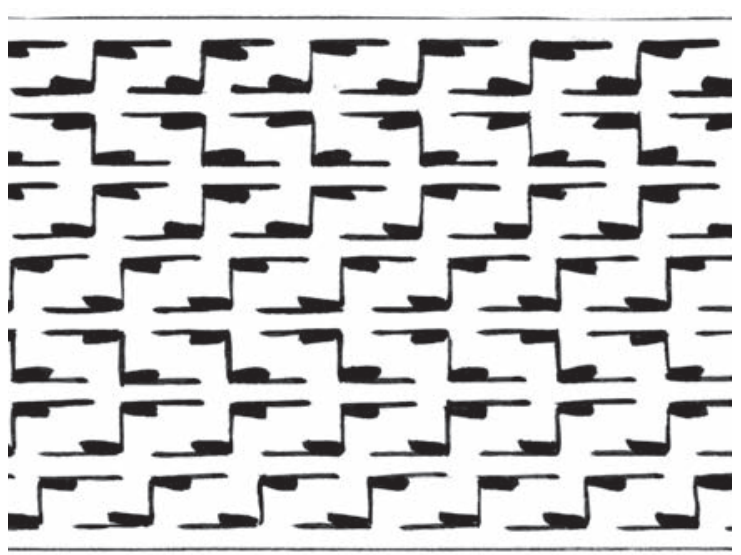

b

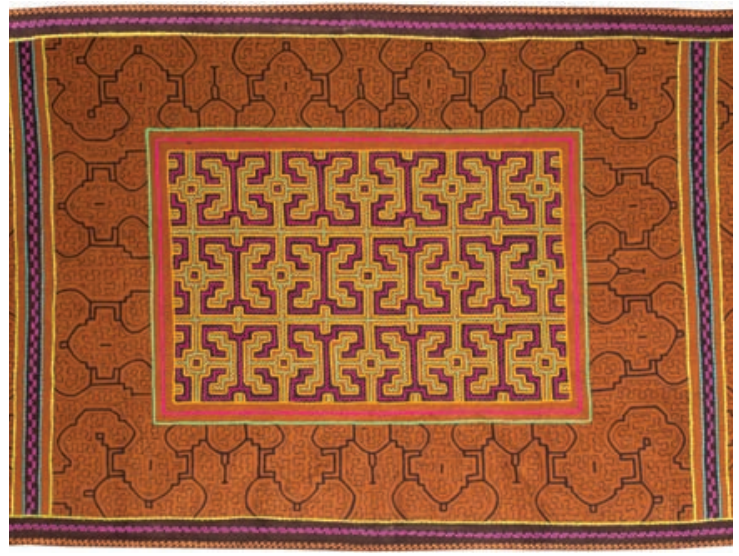

Figura 13. Ilusión óptica de movimiento y vibración: a) patrón Diaguita Líneas quebradas C1 (González 2013: 145); b) textil Shipibo, comunidad de Panaillo (colección Paola González). Figure 13. Optical illusion of movement and vibration: a) Diaguita C1 broken line pattern (González 2013: 145); b) Shipibo textile, Panaillo community (Paola González collection).

\section{ANTECEDENTES ARQUEOLÓGICOS DE LA CULTURA SHIPIBO-CONIBO Y POSIBLE EXIS- TENCIA DE UN ANCESTRO COMÚN ENTRE LA CULTURA CUMANCAYA Y LA CULTURA DIAGUITA CHILENA}

Diversos autores han planteado que la cultura Cumancaya es el ancestro cultural de la cultura Shipibo-Conibo. Es por esta razón que la abordaremos con mayor detalle.

\section{Tradición Cumancaya}

Esta tradición fue definida por Lathrap (1970) en el Ucayali central, y fue complementada por las investigaciones de Raymond, De Boer y Roe (1975) en el alto Ucayali. Morales Chocano (2011: 148) precisa que esta fase comenzaría en el año 800 DC, cuando en el sitio de origen mítico de los shipibo-conibo. llamado Cumancaya, se reunieron tres estilos de diferentes orígenes: (1) La cerámica roja entre incisiones, asociada a los santuarios de Upano en Sangay (Ecuador), (2) la cerámica de engobe rojo y adornos zoomorfos del estilo Pacacocha del Ucayali y (3) la cerámica de estilo corrugado que llega tardíamente de la Amazonía boliviana.

Lathrap plantea que "un buen número de líneas de evidencia indican que el pueblo Cumancaya fue el ancestro de los grupos de habla Pano en el Valle de Ucayali y los sectores adyacentes de las cuencas de Purús y Juruá. La fecha de la invasión Cumancaya concuerda bien con las leves diferencias entre los lenguajes pano del norte" (1970: 140).
Por su parte, Morales (2011: 148) agrega que la diversidad cultural y el multilingüismo en la Amazonía peruana comenzaría con esta fase. La tradición también comparte con el pueblo shipibo la práctica de entierros secundarios en urnas de cerámica, deformación craneana y artefactos utilizados en ritos de pasaje, específicamente la fiesta de pubertad de las niñas (Anisheati).

La tradición Cumancaya se asocia a grandes asentamientos ribereños representados en sitios como Cumancayacocha, Zapotal y Caimito en la cuenca del Ucayali, con una economía estable de agricultura en tierras inundables y abundancia de pesca, complementada por caza y recolección en los bosques. Lathrap plantea que

\footnotetext{
es fácil observar cómo la industria cerámica que sobrevive en las tribus Pano en la cuenca del Ucayali deriva de la cerámica Cumancaya. Aunque existen variaciones de un grupo a otro, cada forma de tratamiento de superficie usado por ellos en sus vasijas tiene su antecedente en la cerámica Cumancaya. Además, los diseños pintados o bordados de los Cashinahua, que poseen el estilo artístico más desarrollado, son similares a los motivos del estilo Cumancaya Chocolate sobre Crema (1970: 140).
}

Pese a que la cerámica del grupo pano shipibo-conibo es más elaborada y divergente que la cerámica Cumancaya -agrega el autor-, un número de continuidades son evidentes. Todas las técnicas decorativas utilizadas por los shipibo-conibos en los utensilios domésticos se encuentran también en la cultura Cumancaya. Por ejemplo, escalonados en ángulo recto, el motivo más productivo Cumancaya, encuentran continuidad en los escalonados de ángulo recto del arte moderno shipibo-conibo (fig. 14). 


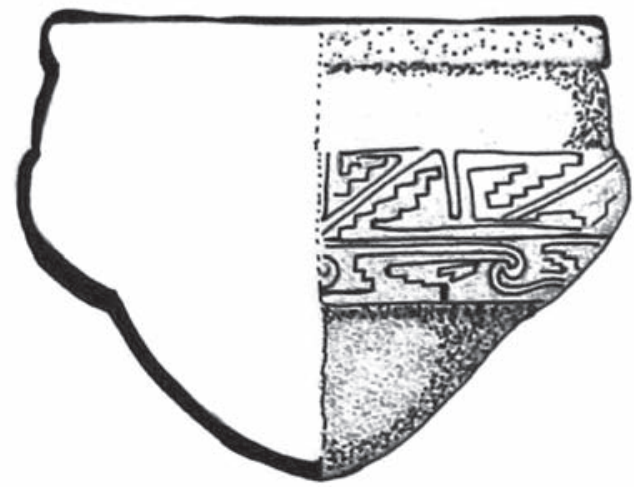

Figura 14. Vasija Cumancaya (Lathrap 1970: 91). Figure 14. Cumancaya vessel (Lathrap 1970: 91).

No obstante, en Cumancaya está ausente la decoración polícroma en negro y rojo sobre blanco, y blanco sobre rojo, característica de la cerámica shipibo-conibo. A este respecto, Lathrap afirma que

las raíces del estilo de alfarería pintada de los shipibo conibo no derivan totalmente de Cumancaya. La afición por las líneas rectas y los motivos escalonados claramente derivan del estilo Cumancaya, mientras que los dos esquemas de color básicos y la insistencia en dos o tres anchuras estandarizadas de líneas pintadas tienen un antecedente claro en los estilos Caimito y Napo. Es sabido que los Shipibos y los Cocama compartieron las mismas misiones durante los siglos XVII a XIX y estos estilos llegaron a amalgamarse (1970: 184).

a

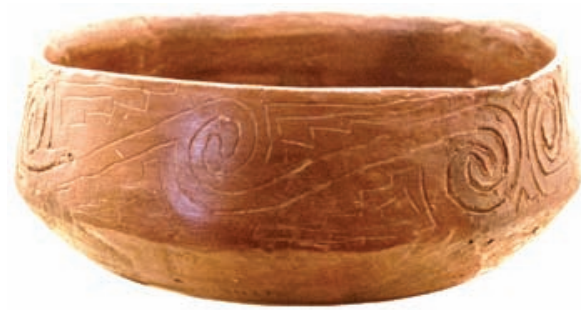

C

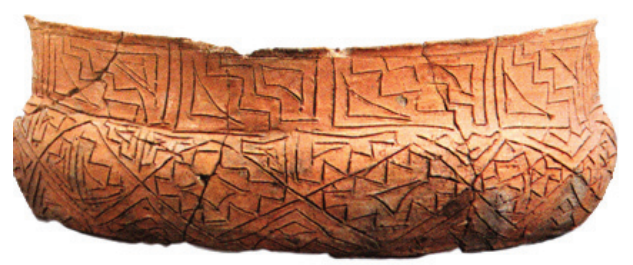

En efecto, durante tiempos prehistóricos tardíos, la cuenca central del Ucayali sufrió dos oleadas de migración. La primera

probablemente vino desde el sur trayendo consigo la tradición cerámica Cumancaya. La última invasión prehispánica provino de la corriente principal del Amazonas compuesta de los hablantes tupí-cocama y omagua quienes conquistaron los territorios y los mantuvieron hasta el momento de producirse los primeros contactos con los europeos (Lathrap 1970: 136).

Por otra parte, resulta sorprendente la estrecha semejanza entre el estilo Cumancaya y la cerámica diaguita. A nivel de decoración, existen numerosas coincidencias en las unidades mínimas utilizadas (grecas escalonadas, triángulos unidos a volutas, escalonados simples) y en los principios simétricos que articulan estas unidades (reflexión desplazada unida a traslación, doble reflexión especular, reflexión horizontal). Asimismo, existe coincidencia también en algunas de sus formas cerámicas (escudillas de perfil compuesto). Pensamos que es muy interesante profundizar en estos paralelos, que podrían aportar información sobre las vinculaciones culturales entre los diaguitas y el antecedente cultural de la cultura Shipibo-Conibo (fig. 15 a-d).

b

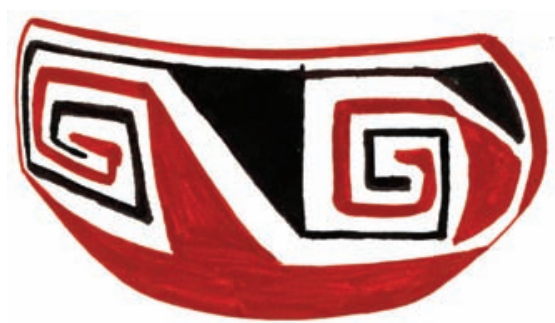

d

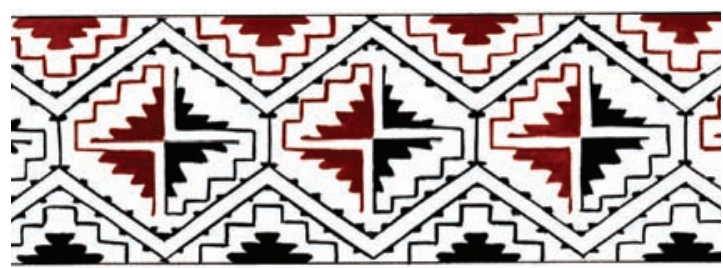

Figura 15. Paralelos en decoración cumancaya y diaguita: a) cerámica cumancaya, Volutas entrelazadas. Museo Nacional de Antropología, Arqueología e Historia, Lima (fotografía de Paola González); b) cerámica diaguita, patrón Cadenas B7 (González 2013: 131); c) vasija cumancaya, Escalonados en doble reflexión especular. Museo Nacional de Antropología, Arqueología e Historia, Lima (fotografía de Paola González); d) patrón diaguita Doble zigzag A2 (González 2013: 131). Figure 15. Cumancaya and diaguita decorative similarities: a) Cumancaya ceramics, Intertwined spirals. Museo Nacional de Antropología, Arqueología e Historia, Lima (photo by Paola González); b) Diaguita ceramic vessel, B7 chain pattern (González 2013: 131); c) Cumancaya vessel, Double stepped mirrored reflection. Museo Nacional de Antropología, Arqueología e Historia, Lima (photo by Paola González); d) Diaguita A2 double mirrored reflection pattern (González 2013: 131). 


\section{Posible ancestro común de la cultura Cumancaya y la cultura Diaguita chilena}

En esta sección, examinaremos los postulados de Lathrap (1970) relativos al probable origen cultural de la cultura Cumancaya que, como veremos, podría ser también un ancestro cultural de los diaguitas chilenos. Las semejanzas descritas y analizadas entre los pueblos diaguita y shipibo podrían ser explicadas, en parte, por la existencia de este ancestro cultural común.

Lathrap (1970: 140-141) señala que "no es fácil plantear cuál fue el origen último del estilo Cumancaya, dado que cerámica similar cuenta con un rango particularmente amplio de distribución a lo largo de las pendientes orientales de los Andes". Al respecto, indica que "vasijas con zonas rojas" asociadas a una decoración de compleja organización y con un limitado número de motivos, entre los cuales encontramos escalonados sobrepuestos ("step frets") y volutas entrelazadas, semejantes a Cumancaya, se encuentran en un conjunto de grupos culturales como el pueblo Mbaya/Caduveo del Matto Grosso brasilero. A este respecto, apreciamos una fuerte semejanza entre los patrones decorativos diaguita preincaicos y caduveo (fig. 16 a-d).

Lathrap propone que "si las semejanzas entre el arte Cumancaya y el arte de los Mbaya/Caduveo no son accidentales, entonces el ancestro del pueblo Cumancaya debió haber estado en contacto con los ancestros Mbaya/Caduveo y otras tribus Guaycuruan del Gran Chaco alrededor del 300-400 DC, antes de producirse el movimiento de la gente Cumancaya hacia la cuenca del Ucayali". Entonces el autor, asociando datos emanados desde una base lingüística, relativos a que el pueblo proto Pano habría tenido como origen "un punto al este de Bolivia", sugiere "mirar al oriente de Bolivia para ver si existe un estilo que podría ser el ancestro tanto del estilo Cumancaya como del moderno estilo Mbaya/Caduveo" (Lathrap 1970: 142). Es así como postula el estilo Mojocoya Trícromo como el ancestro de la cultura Cumancaya.

\section{Estilo Mojocoya trícromo}

El estilo Mojocoya trícromo se encuentra presente en las pendientes orientales de los Andes bolivianos, específicamente en el departamento de Chuquisaca en las cabeceras del río Pilcomayo (Lathrap 1970: 144). Aclara el autor que "sobre la base del trabajo de Ryden \&
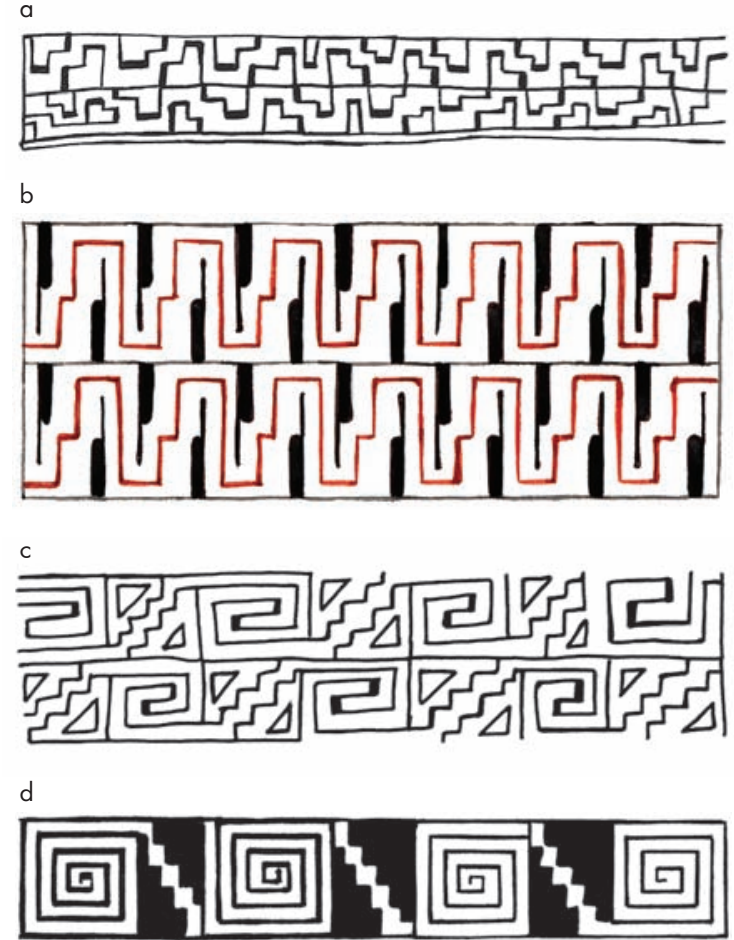

Figura 16. Paralelos en decoración caduveo y diaguita: a) patrón Doble Zigzag Caduveo (Lathrap 1970: 141); b) patrón Diaguita Doble Zigzag A2 (González 2013: 94); c) patrón Laberinto Caduveo (Lathrap 1970: 141); d) patrón Diaguita Laberinto B (González 2013: 153). Figure 16. Caduveo and Diaguita decorative similarities: a) Caduveo double zigzag pattern (Lathrap 1970: 141); b) Diaguita A2 double zigzag pattern (González 2013: 94); c) Caduveo labyrinth pattern (Lathrap 1970: 141); d) Diaguita labyrinth B pattern (González 2013: 153).

Walter sabemos que el estilo Mojocoya trícromo floreció antes de la expansión del estilo Tiwanaku fuera de la cuenca del Titicaca, situándose entre el 300-400 DC. Se caracteriza por construir sus diseños con un limitado rango de motivos, consistentes en volutas entrelazadas y escalonados sobrepuestos" (1971: 143). Asimismo, destaca que el río más importante del Gran Chaco es el Pilcomayo, el que constituye la ruta principal que conecta con las pendientes orientales de los Andes. Asimismo, recuerda que los Mbaya/Caduveo tuvieron su origen en el Gran Chaco y solo en tiempos históricos se trasladaron a Brasil.

El autor plantea que, aun si descartáramos completamente las semejanzas estilísticas entre Cumancaya y el estilo Mojocoya trícromo, existen otras razones que avalan su hipótesis. Por ejemplo, la cerámica corrugada es muy común en esta área; en el caso del complejo del 
Río Palacios, este "no solo posee un corrugado idéntico al de Cumancaya sino que prácticamente duplica el rango de formas de vasijas" (Lathrap 1970: 144). Agrega que la inflexión hacia la base que presentan las grandes urnas Cumancaya también se encuentra en los materiales del río Palacios y en otros estilos cerámicos más sureños, que incluyen el estilo Candelaria en el noroeste argentino. Es decir, estas relaciones entre distintos ámbitos de su arte y cultura material avanzan hacia el sur hasta áreas que tradicionalmente han mantenido contactos con el norte semiárido chileno. De acuerdo a lo expresado por Lathrap, otra evidencia sobre materiales semejantes "no se encuentra, hasta donde alcanza mi conocimiento, al norte de la cuenca del Ucayali o en los Andes septentrionales o centrales" (1970: 144).

En apoyo a las ideas de Lathrap (1970) acerca de que el origen de la cultura Cumancaya (ancestro cultural de los Shipibo-Conibo) se encontraría en el estilo Mojocoya trícromo, aportamos la constatación de un parentesco estilístico y estructural (sensu Washburn 1977, Washburn \& Crowe 1988) sobresaliente entre este estilo y el arte visual de la cultura Diaguita chilena (fig. 17 a-f). Desde el punto de vista estructural, llama poderosamente la atención que no existe solo una coincidencia respecto de las unidades mínimas empleadas, sino también respecto de los principios simétricos que las gobiernan. Así, se distinguen en el estilo Mojocoya trícromo varios patrones decorativos simétricos presentes en el arte diaguita preincaico. En definitiva, planteamos que, pese a la distancia cronológica y espacial entre la cultura prehispánica Diaguita chilena y la cultura etnográfica Shipibo-Conibo, de la Amazonía peruana, las semejanzas estructurales de su arte visual y la existencia de prácticas culturales vinculadas al chamanismo sugieren una relación que amerita ser considerada más detenidamente.

Washburn (1977) ha destacado que la simetría es una formidable herramienta para dar cuenta de interacciones culturales, dado que cada cultura selecciona un número determinado de simetrías y unidades mínimas, generando configuraciones distintivas que contribuyen al proceso de autoidentificación. En el caso de la cultura Mojocoya, tanto la variable cronológica como espacial nos sugiere que podría constituir el ancestro común de diaguitas y shipibos. No obstante, debemos desarrollar una mejor comprensión de esta manifestación cultural del oriente boliviano desde el punto de vista iconográfico y contextual, a fin de precisar el alcance de aquella relación. Por ejemplo, comprender los procesos migratorios que afectaron al área amazónica, el desplazamiento de estas culturas afines, sus condicionantes externas, etc. Pensamos que se trata de una primera aproximación a un tema trascendente que puede derivar en una mejor comprensión del origen de la cultura Diaguita en el norte semiárido chileno, pues relaciona esta cultura con un pasado de más largo alcance espacial y cronológico, que apunta a las tierras bajas al oriente de los Andes.

\section{CONCEPTO DE ARTE EN LA CULTURA SHIPIBO-CONIBO Y SU APORTE PARA LA COMPRENSIÓN DEL ARTE VISUAL DIAGUITA PREINCAICO}

La cultura Diaguita chilena ha dejado un enorme legado de arte visual; sin embargo, aún estamos lejos de comprender a cabalidad su rol social. Es por esta razón que la información sobre arte y contexto cultural shipibo-conibo es relevante, en cuanto aporta caminos interpretativos que enriquecen nuestra apreciación del arte diaguita preincaico.

\section{Concepto de arte en la cultura Shipibo- Conibo}

La extraordinaria complejidad y belleza del arte shipibo y sus múltiples manifestaciones en la cultura material dan cuenta de su importancia en esta sociedad. Se trata de comunidades en que la belleza camina junto a la percepción de lo sagrado, en que no existe una línea divisoria clara entre la experiencia religiosa y la experiencia estética. Los diseños abstractos y simétricos tienen una finalidad esencialmente estética y terapéutica. El kené no cumple solo una función estética; también está destinado a ser un agente activo en la protección y mantención de la salud física y espiritual de los shipibos.

Belaunde (2009: 15) se refiere a los diseños shipibos o kené indicando que:

tanto en la materialización de los diseños hechos sobre los cuerpos como en la visión inmaterial de los diseños durante las sesiones chamánicas se trata de embellecer a las personas y las cosas, envolviéndolas con los grafismos de la energía de las plantas y, por medio de este embellecimiento, curarlos de males diversos de origen físico, psicológico, social y espiritual (2009: 22). 

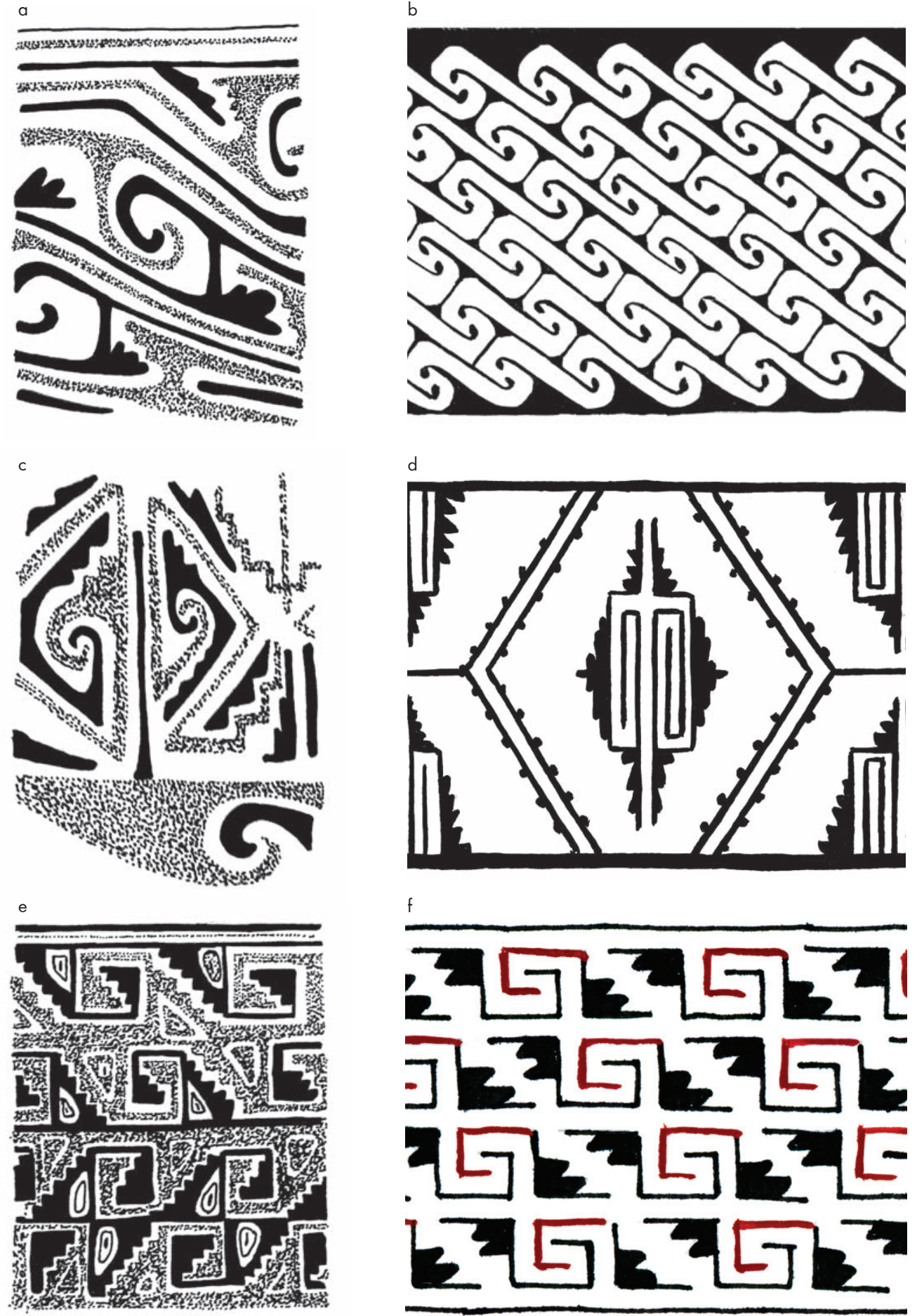

Figura 17. Paralelos estilo Mojocoya Trícromo y Diaguita preinca: a) diseño Mojocoya Trícromo (Lathrap 1970: 143); b) patrón Diaguita Ondas A1-1 (González 2013: 105); c) diseño Mojocoya Trícromo (Lathrap 1970: 143); d) patrón Diaguita Escalonado en Reflexión Vertical (González 2013: 288); e) diseño Mojocoya Trícromo (Lathrap 1970: 143); f) patrón Diaguita Cadenas C1-1 (González 2013: 131). Figure 17. Stylistic similarities between Mojocoya Tricolor and Diaguita pre-Inca designs: a) Mojocoya Tricolor design (Lathrap 1970: 143); b) Diaguita A1-1 wave pattern (González 2013: 105); c) Mojocoya Tricolor design (Lathrap 1970: 143); d) Diaguita stepped pattern in vertical reflection (González 2013: 288); e) Mojocoya Tricolor design (Lathrap 1970: 143); f) Diaguita C1-1 chain pattern (González 2013: 131). 
Se trata de un arte estrechamente ligado a prácticas chamánicas, consumo de alucinógenos (ayahuasca) y estrategias de sanación de índole sinestésica, en que se oscila entre expresiones visuales, musicales y coreográficas. Esta unión de estética y medicina puesta en acción en los diseños comporta una dimensión musical esencial: cada diseño es también un canto (íkaro) que interpreta el chamán en su ritual de sanación. A su vez, la ayahuasca manifiesta los poderes curativos de la anaconda primordial (Ronin), generadora y madre de todos los diseños (Belaunde 2009).

Sin embargo, las mujeres shipibos se auxilian también de la observación de la simetría natural presente en su entorno (fig. 18 a, b). A este respecto, Barbec de Mori y Mori de Barbec (2009: 111) señalan lo siguiente:

\begin{abstract}
las mujeres shipibo han seguido perfeccionando su arte a través de varias técnicas, sobre todo orientándose con la observación de la naturaleza. Muchas plantas o animales muestran kené, principalmente la anaconda (rono ewa, ronin) que es considerada la "madre de los diseños". El pez Ipo lleva diseños en su cabeza. La planta Ipo Kené, con su mismo nombre indicando claramente su significado, entre otras servía para eso, como las telas de araña, o las pisadas de las garzas en las arenas de las playas.
\end{abstract}

Claramente, el kené no cumple solo una función estética, sino que también está destinado a ser un agente activo en la protección y mantención de la salud física y espiritual de los shipibos. En este sentido, los postulados de Gell, relativos a la agencia del arte y su concepto de "tecnologías de encantamiento" (Gell 1998: 72) resultan particularmente sugerentes para acercarse al sentido y función social de la cultura material Shipibo, decorada con patrones simétricos.
La cultura material no es un reflejo pasivo de la conducta humana, sino una práctica social activa, "constitutiva de un orden social" (Preucel 2006: 5). La cultura material, en particular el arte visual, es una arena propicia para acceder a dimensiones intangibles que enriquecen nuestra comprensión de las sociedades pasadas. Preucel señala que "uno de los más excitantes desarrollos en la antropología contemporánea es el naciente interés en los estudios relativos a la cultura material" (2006: 14), así como la comprensión de su rol activo en la generación de procesos sociales. Existe un creciente reconocimiento de que los objetos no son reflejos pasivos de la sociedad, sino que son participantes activos de las prácticas sociales que los constituyen ya que, a su vez, estos objetos constituyen y determinan dichas prácticas sociales. De acuerdo a Strathern (1988), en el proceso de hacer los objetos, la gente se hace a sí misma.

\section{"Tecnologías de encantamiento" en el arte shipibo- conibo}

Planteamos que la cuidadosa decoración de diversos soportes con complejos diseños simétricos, observada en la cultura Shipibo, reviste a estos objetos de agencia social, transformándolos en agentes sociales que cumplen un rol activo en la conservación y reactualización de su cultura.

En relación a las obras de arte, Gell destaca el concepto de cautivación, según el cual, por medio de la destreza técnica y una sobresaliente imaginación, se "explotan mecanismos intrínsecos de cognición visual con sutiles ribetes sicológicos, que devienen en obras de arte que poseen agencia artística”. Agrega el autor a

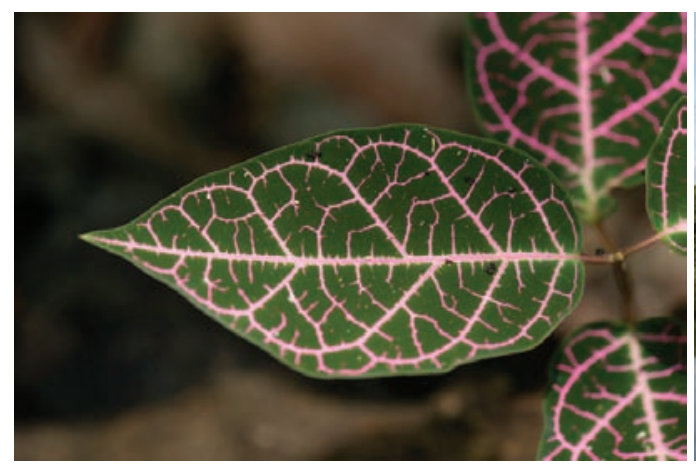

b

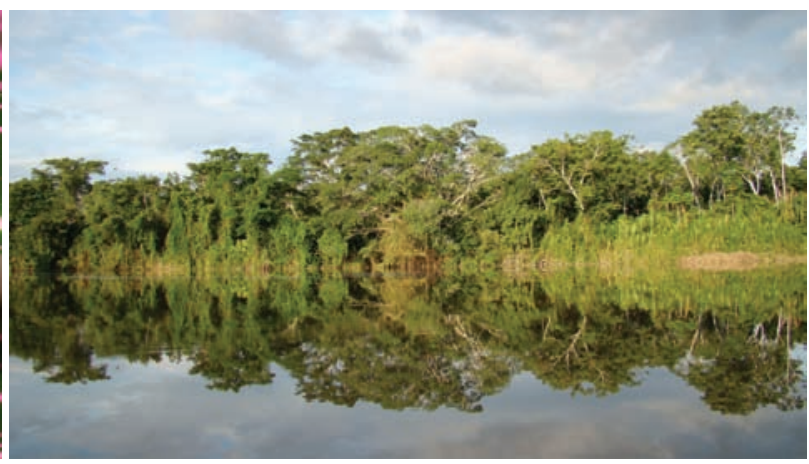

Figura 18. Simetría en el ambiente shipibo: a) hoja de Ipó Kené (fotografía de Nicolás Aguayo); b) paisaje del río Ucayali (fotografía de Paola González). Figure 18. Symmetry in the Shipibo environment: a) Ipó Kené leaf (photo by Nicolás Aguayo); b) Ucayali River landscape (photo by Paola González). 
que la cautivación "está presente también en aquellos artefactos que se anuncian a sí mismos como creaciones milagrosas, donde su poder reside en el hecho de que su origen es inexplicable, excepto como algo mágico o sobrenatural" (1998: 68). Se trata de "trabajos mágicoartísticos" (1998: 71). Las obras de arte decoradas con patrones abstractos de simetría compleja producen una suerte de "bloqueo cognitivo" en el espectador, al verse aquel imposibilitado de seguir la secuencia de pasos que le dan a la obra de arte su actual fisonomía.

De acuerdo a Gell, las obras de arte son objetos "característicamente 'difíciles"' (de hacer, de pensar, de transar). Ellos fascinan al espectador. Su peculiaridad, intransigencia y belleza son factores claves de su eficacia como instrumentos sociales" (1998: 23). En particular, el arte abstracto explota nuestra percepción de una agencia interna porque "los patrones, por su multiplicidad y la dificultad que tenemos en captar su base geométrica o matemática por la mera inspección visual, generan una relación en el tiempo, entre personas y cosas, porque lo que ellos presentan a la mente es, cognitivamente hablando, un "asunto pendiente" (1998: 80). Esto, a juicio del autor, "establece una relación biográfica - un intercambio inacabadoentre el indicador decorado y el recipiente" (1998: 81). Entonces, atribuye aquella "adhesividad cognitiva" de los patrones abstractos "a este proceso de bloqueo cognitivo al intentar reconstruir la intencionalidad encarnada en los artefactos" (1998: 86).

Gell sostiene que el arte decorativo es una forma especial de tecnología. Agrega que "la decoración de objetos es un componente de una tecnología social, la cual he llamado tecnología del encantamiento (Gell 1992). Esta tecnología sicológica alienta y sostiene las motivaciones necesarias para la vida social" (1998: 74). En otras palabras, la decoración sería esencial para la funcionalidad sicológica y social de los artefactos.

Por ejemplo, mediante el empleo de estrategias visuales, los patrones abstractos adquieren propiedades tales como ilusión de movimiento y vibración, que contribuyen a la cautivación del espectador y a la agencia del patrón. Señala Gell que "nada es más animado que las teselaciones (patrones de mosaico) desarrolladas por los artesanos islámicos. Ellos actuaron como incentivos para la cautivación, a través de artificios visuales, como la aparición no mimética de animación”. De este modo, "agencia y movimiento parecen inherentes a los motivos en sí mismos” (1998: 77).
En mi opinión, podemos observar estas "tecnologías de encantamiento" en las características intrínsecas del arte visual, de esta específica tradición de arte chamánico sudamericano a la que me he referido anteriormente (González 2013), tradición a la cual pertenecería el arte visual shipibo-conibo y diaguita preincaico. Estas estrategias visuales o técnicas consisten en el empleo de simetría compleja, horror vacui, visión en positivonegativo, repetición periódica, poder autogenerador de los diseños, interminable variabilidad, complicación estructural gradual, atracción hipnótica e ilusión óptica de movimiento y vibración.

\section{Agentes sociales humanos y entidades tutelares en el arte y cosmovisión shipibo- conibo}

Los agentes sociales humanos que participan en la elaboración y despliegue social del estilo de arte visual shipibo conibo son las mujeres artesanas, por una parte, quienes conciben los patrones decorativos abstractos y simétricos y los ejecutan en distintos soportes, y el chamán quien participa de la terapia de sanación mediante el consumo de ayahuasca, la visualización de patrones simétricos sanadores y la interpretación de cantos ( $i k a-$ ros), vinculados con estos diseños. Sin embargo, el arte visual shipibo (y su eficacia en las terapias chamánicas de sanación) se encuentra mediado también por un conjunto de entidades tutelares del ámbito sagrado y mágico-religioso que participan activamente y ayudan al chamán (meraya) en su labor de sanación.

A este respecto, Illius informa que "algunos seres míticos son vistos como los 'señores' de los quené, así por ejemplo el poderoso colibrí (pino ehua), el señor de la liana ayahuasca (nishi ibo), y sobre todo, el más respetado y temido de todos: ani ronin, la gran boa" (1991-1992: 25). Destacamos que los patrones decorativos abstractos (kené), en sí mismos, son considerados como sagrados y con agencia social. A continuación, revisamos cuatro de ellos.

\section{Kené o patrones decorativos abstractos y simétricos}

Entre los shipibo-conibos, existe al nacer una suerte de "marcaje" invisible de las personas con patrones decorativos. En estado de enfermedad, los diseños sanadores son espiritualmente proyectados sobre el paciente por el chamán para reestablecer la salud. Los 
shipibo-conibo perciben la enfermedad "como una mancha u obstrucción en el diseño que impide el flujo de energía. Durante la curación el chamán trata de alinear los diseños para fortalecer la energía vital" (Heath 2002: 49). Al principio, el cuerpo del enfermo aparece como un diseño muy desordenado, desarmado, pero a medida que avanza el tratamiento, y mediante la traducción del patrón decorativo a cantos (íkaros), el diseño va reapareciendo gradualmente. Cuando el paciente es sanado, el diseño se vuelve claro y discernible.

La atribución de agencia al patrón simétrico es evidente en el relato de Netén Vita (chamán shipibo de Caimito) consignado por Illius (1994: 197). Netén Vita señala que para sanar debe contactar a los espíritus tutelares: "las tiras de dibujos de mi cielo (noco naina kené)". Por su parte, Gehbart-Sayer (1985: 164) menciona el diseño "nai cano mahueca", que significa "curvas consecutivas en el andamiaje del cielo" y sirve para sanar la fiebre hemorrágica.

Gell plantea que: "El arte decorativo involucra el uso de patrones que explotan relaciones, parte a parte, particularmente sobresalientes visualmente, producidas por la repetición y ordenamiento simétrico de los motivos" (1998: 76). Así se conciben efectos de animación no mimética que refuerzan la agencia del patrón ante los espectadores (fig. 19).

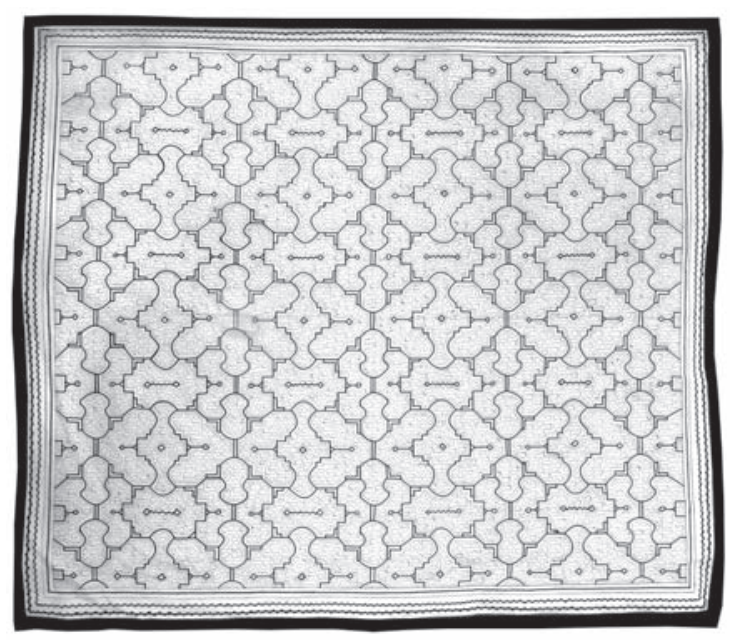

Figura 19. Tela shipibo pintada con diseño kené (colección Paola González. Figure 19. Shipibo cloth painted with kené design (Paola González collection).

\section{Anaconda cósmica o Ronin}

Gebhart-Sayer señala que "Ronin es un espíritu principalmente relacionado con el agua y la base física del universo. Es fuente de todos los productos acuáticos y madre de todas las criaturas del agua" (1986: 192). En el arte shipibo-conibo, Ronin es simbolizado en tres niveles. Por una parte, se percibe en la manufactura de vasijas de cerámica. En efecto, "los rollos de barro añadidos representan la anaconda enrollada, descansando. Los rollos de barro rodean la esfera de la vasija del mismo modo en que Ronin rodea el cosmos, así que el chomo (ánfora del masato) sirve como parábola de la gran bóveda cósmica" (1986: 192). Asimismo, el arte visual, como un todo, se relaciona con la piel de Ronin donde se encuentran todos los diseños imaginables (1986: 192). Finalmente, Ronin y otras serpientes también son representadas en motivos individuales más o menos estilizados, de forma ofidia, que se integran al diseño.

Por otra parte, Belaunde (2011: 476) cita a Valenzuela y Valera (2005: 62), quienes señalan que "el diseño es lo que con su belleza nos hipnotiza, luego se convierte en yacumama [anaconda ronin]. La misma yacumama [anaconda ronin] es nuestro diseño".

\section{Espíritu de la ayahuasca (Nishi Ibo)}

En la terapia de sanación, otra entidad sagrada participante es el espíritu de la ayahuasca (Nishi Ibo). Señala Gebhart-Sayer que "este espíritu proyecta figuras geométricas luminosas frente a los ojos del chamán: visiones de ondulación rítmica, ornamentación fragante y luminosa" (1986: 196). El trance alucinógeno se encuentra marcado por la experiencia sinestésica, según la cual las canciones "se escuchan, se ven se huelen y se cantan simultáneamente por todos los involucrados: Nishi Ibo, los demás espíritus presentes y el chamán" (1986: 196).

\section{Colibrí (Pino)}

El colibrí ayuda al chamán redibujando los diseños sanadores que se encuentran borrados o "enredados", producto de la enfermedad que afecta al paciente. Gebhart-Sayer explica que

el espíritu del colibrí, Pino, considerado el "escribano" o "secretario" de los espíritus ayudantes, se coloca entonces sobre el paciente y deja caer las configuraciones sobre el cuerpo de éste, siseando, zumbando, canturreando, ocupado 
en realizar pequeños movimientos. El diseño que Pino genera delinea de manera muy personal el shina (mente, conciencia, vitalidad, espíritu) del paciente, así como la terapia que debe seguir (1986: 197).

El arte visual shipibo posee también un uso apotropeico, en el sentido de proteger de la maldad circundante a quien porta estos diseños. En relación al arte visual shipibo, Girard (1958: 239) indica que "su presencia en las prendas de vestir, en la cerámica, en las canoas, en las armas, y en el propio cuerpo tiene el carácter de talismán protector. Y tratando de encontrar el origen de estos símbolos, mis informantes shipibo sólo me expresan que "Dios les ha dado esos dibujos". Heath (2002: 59) también destaca que "los diseños no son un mero registro: tienen shama 'potencia acumulada', transforman y curan el mundo, embelleciéndolo, y como las plantas, retoñan" (fig. $20 \mathrm{a}, \mathrm{b}$ ).

\section{Concepto de arte del pueblo shipibo y aporte del perspectivismo amazónico a su mejor comprensión}

Consideramos de interés integrar a esta reflexión un conjunto de nuevas perspectivas y avances teóricos acerca de las tradiciones chamánicas amazónicas y su particular visión de mundo, surgidas a partir del estudio de pueblos actuales en distintas regiones de la Amazonía. A partir de los estudios de Lathrap (1970), diversos estudios etnográficos sobre la cosmovisión de distintos pueblos amazónicos revelaron una serie de constantes que permiten postular la existencia de un conjunto de creencias de carácter panamazónicas (Barreto 2008), plasmadas en diferentes estilos. Por una parte, la reiterada presencia y representación de determinados animales, principalmente felinos y serpientes, unida al desarrollo de arte abstracto y prácticas chamánicas, evidencian un marco ideológico común de gran complejidad y originalidad. De acuerdo a Barreto, "la iconografía de los objetos se identifica como esencialmente religiosa con base en prácticas alucinógenas y chamanísticas, utilizada en rituales para comunicarse con el mundo sobrenatural (Lathrap 1970). En resumen, se trata de un estilo que puede ser un replicador de la ideología" (2008: $21,22)$. Estas características pueden ser trazadas tanto en culturas presentes como en el pasado arqueológico (Reichel-Dolmatoff 1978; Roe 1982; De Boer 1984). A este respecto, Taylor señala que "es posible que lo que vemos de la tradición gráfica contemporánea amazónica sea solamente la conservación de una tendencia presente en tiempos precolombinos, fruto de una tradición cultural antigua. La de una forma de arte sumamente intelectual, cerebral, elaborado y complicado" (2008: 16).

De este modo, la etnografía amazónica aportó elementos a Viveiros de Castro (1998) para el desarrollo de la teoría denominada perspectivismo amazónico. El autor plantea que "los amerindios son cosmocéntricos, es decir, nunca distinguieron entre humanos y animales, para ellos naturaleza y cultura son partes del mismo campo sociocósmico" (1998: 475). Es decir, existe una mixtura entre sujeto y objeto. Esta teoría tiene un vínculo "esencial con el chamanismo y con la valorización de la caza" (1998: 472). De acuerdo con Viveiros de Castro, los pueblos amazónicos conciben al otro -sea este un humano, animal, artefacto, fenómeno meteorológico, planta, etc.- de una manera diversa a la forma en que estos seres o entidades perciben a los humanos o a ellos mismos. En otras palabras, los seres que son percibidos como iguales al observador son considerados como humanos, y el resto es percibido como predador o presa. Viveiros de Castro agrega que

\begin{abstract}
esta noción se asocia siempre a la idea que la forma manifiesta de cada especie es un mero envoltorio ("ropaje"), el cual oculta una forma humana interna, usualmente solo visible a los ojos de especies particulares o de ciertos seres trans-específicos tales como los chamanes. La forma interna es el "alma" o "espíritu" del animal: una intencionalidad o subjetividad formalmente idéntica a la consciencia humana, materializable (1998: 471).
\end{abstract}

Se trata de un universo "altamente transformacional" (sensu Riviére 1994: 256), propio de la cosmovisión amazónica.

Por su parte, en el ámbito del arte, Barreto (2008: 28) destaca los postulados de Els Lagrou sobre el arte visual kaxinawá, marcado por una "compulsión decorativa", característica también observada entre el pueblo shipibo. De acuerdo a Lagrou, en la percepción amazónica, "el mundo está compuesto de muchos mundos, y estos mundos diversos son pensados como simultáneos y en contacto, pero no siempre perceptibles. El papel del arte sería entonces, el de comunicar una percepción sintética de esta simultaneidad de diferentes realidades" (2007: 149).

Taylor (2008) profundiza aun más en el sentido y alcance del arte amazónico, a partir de los postulados teóricos recién reseñados. Por una parte, la autora destaca que el arte visual amazónico es escaso en re- 

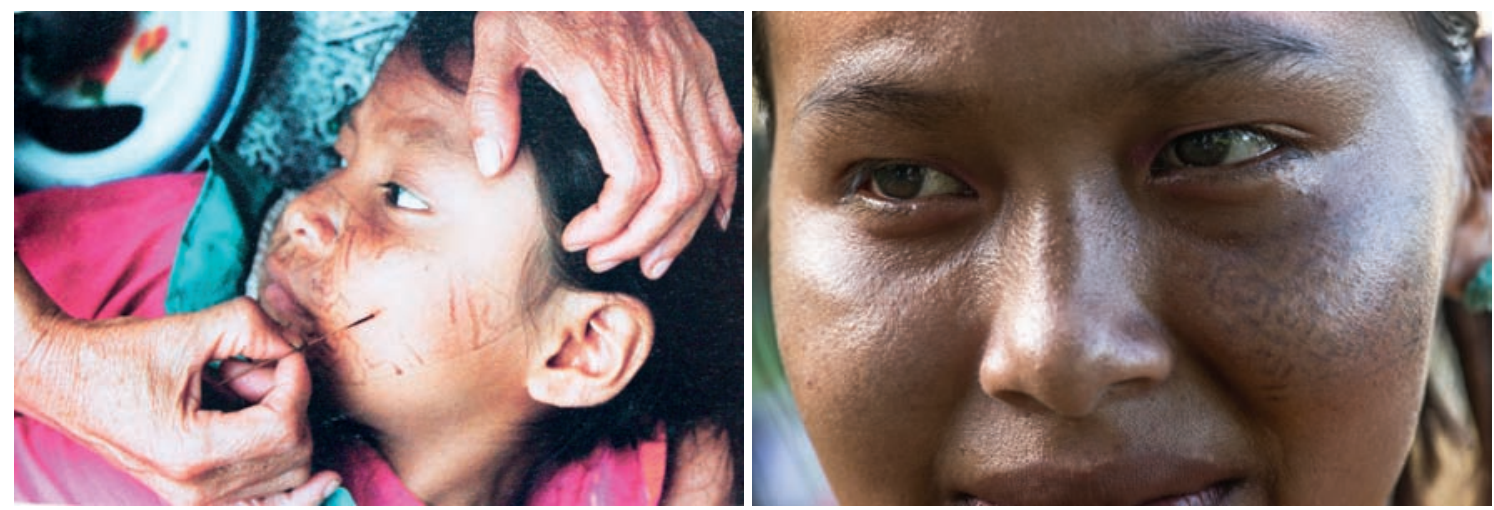

Figura 20: a) pintura corporal de huito (en Belaunde 2009: 47); b) pintura facial (fotografía de Nicolás Aguayo). Figure 20: a) Huito body paint (in Belaunde 2009: 47); b) face paint (photo by Nicolás Aguayo).

presentaciones figurativas de los seres o entidades que pueblan su cosmovisión, al contrario de las numerosas representaciones no figurativas y geométricas presentes en su iconografía. Ella se pregunta, entonces, si la tradición chamánica amazónica es efectivamente "iconofóbica" (2008: 2). Se refiere, por ejemplo, a la pintura corporal, la cual vincula a "nociones de identidad y, más generalmente con el status ontológico del sujeto portador" (2008: 3). Agrega que "para los indígenas amazónicos todos los seres y los sujetos, todos los seres animados -sean animales, vegetales o humanos-, incluyendo espíritus, lucen pintura corporal aunque los hombres no nos percatemos de ello" (2008: 4). La autora destaca la importancia esencial que reviste la ornamentación y la pintura corporal entre los pueblos amazónicos, por tratarse de una práctica cultural que determina el "estado de humanidad" (2008: 5). Antecedentes semejantes aporta Lévi-Strauss, sobre la importancia cultural que reviste la pintura corporal para los indígenas Caduveo, quienes no consideraban humanos a quienes no la poseían, o como lo indica el autor, "había que estar pintado para ser hombre" (LéviStrauss 1992: 194). Entonces, a la luz de los postulados perspectivistas, Taylor concluye que "de manera inversa, cualquier superficie con motivos geométricos puede evocar subjetividad o personalidad. Incluso las pinturas mismas pueden ser tratadas como personas. Por ejemplo, entre los Jíbaros hay cantos rituales dirigidos directamente a pinturas corporales para pedirles cierto tipo de agencia, acción" (2008: 6).

Entonces, la autora plantea que la pintura corporal abstracta de los grupos amazónicos estaría destinada a "la representación de seres totales como 'corporaliza- ciones'. Unas 'corporalizaciones' de seres no humanos surgidas de la imaginación visual de los indígenas, una materialización de las imágenes mentales" (Taylor 2008: 13). La idea que subyace a dichos postulados es que este arte abstracto-geométrico no sería "iconofóbico", sino que, por el contrario, "tiene un papel muy importante en la perpetuación de esta tradición de imaginar figurativamente seres sobrenaturales" (2008: 13). Así, el sentido y detonante de la tradición visual que genera este arte no figurativo y geométrico sería "imaginar ornamentaciones corporales de una variedad más o menos infinita" (2008: 15). De este modo, desde el punto de vista de sus ejecutores, este arte no figurativo apunta a la representación de ornamentos de los seres sobrenaturales que pueblan su cosmovisión.

\section{CONCLUSIONES}

En el presente trabajo hemos planteado la existencia de un vínculo cultural entre el arte diaguita preincaico y el arte etnográfico shipibo-conibo, apoyándonos en la semejanza iconográfica y estructural de su arte visual, así como en elementos contextuales y cultura material. Por otra parte, el examen de los antecedentes arqueológicos de la cultura Shipibo-Conibo, particularmente la culturas Cumancaya (Lathrap, 1970) y Mojocoya, aportaron nuevos elementos que apoyan esta relación cultural, sugiriendo la existencia de un ancestro común entre ambas y la existencia de una tradición estilística mayor, cuyas raíces se internan profundamente en el pasado prehispánico sudamericano, cuestión que amerita ser investigada con mayor profundidad. 
Cuando nos enfrentarnos a la enorme riqueza y complejidad del universo representacional diaguita, resulta muy difícil acceder a su concepto de arte, premunidos únicamente de las evidencias materiales arqueológicas. El concepto indígena de lo estético que subyace a estas representaciones se presenta evasivo y hermético. Es por esta razón que el examen del arte y contexto cultural en que se inserta el arte shipibo-conibo resulta relevante, en la medida que aporta caminos interpretativos que enriquecen nuestra comprensión del arte diaguita arqueológico.

¿Para qué sirve entonces el arte diaguita? Los artesanos diaguitas exploran con maestría las interminables posibilidades de variación simétrica. Esta actividad demanda el desarrollo de una geometría ancestral y un acabado conocimiento de las leyes de simetría. Este marcado esfuerzo por explorar los derroteros del diseño abstracto no es casual; por el contrario, por medio de este esfuerzo cultural colectivo se definen identidades $\mathrm{y}$ se aprehenden conocimientos.

Por su parte, la evidencia etnográfica apunta a un arte estrechamente vinculado al ámbito sagrado: sus autores son artistas chamanes, "expertos prestidigitadores de imágenes abstractas con un fin que va más allá de la armonía formal” (González 2006: 160). Así, estas obras de arte "mágico-artísticas" se insertan en un contexto de prácticas chamánicas e ingesta de alucinógenos. Por su parte, la evidencia etnográfica apunta a que ellas serían "corporizaciones" de los seres humanos y no humanos que pueblan la cosmovisión amazónica. Asimismo, sus características intrínsecas contribuyen a la cautivación producida en el espectador, al exhibir características de animación no mimética (ilusión de movimiento y vibración, por ejemplo), de difícil explicación para quien las observa. De acuerdo a Gell (1998: 86), ellas producen un "bloqueo cognitivo" que favorece el establecimiento de una "relación en el tiempo" entre obra de arte y receptor, y refuerzan su agencia.

Resulta claro que las imágenes obtenidas por intermedio del trance alucinógeno actúan como estímulo para la experimentación en el arte visual abstracto. No obstante, la etnografía shipibo agrega un elemento relevante, que vincula estética con medicina. Se trata de un concepto de belleza que camina unido a la sanación y lo sagrado, en el que los mecanismos sinestésicos permiten transitar entre el medio visual, auditivo y coreográfico (los patrones decorativos también se danzan). Resulta muy interesante que las visiones de trance alucinógeno producidas por la ingesta de ayahuasca deriven en un concepto tan innovador de arte, que funde y amalgama ciencia (medicina y simetría), religión y estética.

RECONOCIMIENTOS Al proyecto FONDECYT 1110125 y a las comunidades shipibo de Panaillo, Saposoa y Callería.

\section{REFERENCIAS}

Barbec de Mori, B. \& L. Mori de Barbec, 2009. La corona de la inspiración. Los diseños geométricos de los shipibo-konibo y sus relaciones con cosmovisión y música. Indiana 26: 105-134. Berlin: Ibero-Amerikanisches Institute.

BARreto, C., 2008. Meios místicos de reproducao social: Arte e estilo na cerámica funerária da Amazonia antiga. Tese para obtenção do titulo de Doutor em Arqueologia. Museo de Arqueologia e Etnologia, Universidade de São Paulo.

Belaunde, L., 2009. Kené: Arte, ciencia y tradición en diseño. Lima: Instituto Nacional de Cultura-Imprenta Talleres de Forma e Imagen Billy Víctor Odiaga Franco.

Belaunde, L., 2011. Una biografía del chitonte: Objeto turístico y vestimenta shipibo-konibo. En Por dónde hay soplo, J.P. Chaumeil, O. Espinosa de Rivero \& M. Cornejo, Eds., pp. 465-486. Lima: Institut Francais d'Etudes Andines-Pontificia Universidad Católica del Perú.

Castillo, G., 1992. Evidencias sobre uso de narcóticos en el norte semiárido chileno, catastro regional. Contribución Arqueológica. Museo Regional de Atacama 4: 94-114.

De Boer, W., 1984. The Last Pottery Show: Sistem and sense in ceramic studies. En The many dimensions of pottery: Ceramics in archaeology and anthropology, S. E. van der Leeuw \& A. C. Pritchard, Eds., pp. 529-571. Amsterdam: Universiteit van Amsterdam.

DE BOER, W., 1990. Interaction, imitation and communication as expressed in style: The Ucayali experience. En The uses of style in Archaeology, M. Conkey \& C. Hastorf, Eds., pp. 82-104. Cambridge: Cambridge University Press.

Gehbart-Sayer, A., 1985. The geometric designs of the shipibo-conibo in ritual context. Journal of Latin American Lore 11 (2): 143-175. California: UCLA Latin American Institute.

Gehbart-SAYer, A., 1986. Una terapia estética. Los diseños visionarios del ayahuasca entre los shipibo-conibo. América Indígena XLVI (1): 189-218.

GeLL, A., 1992. The technology of enchantment and the enchantment of technology. En Anthropology, Art and Aesthetics, J. Coote \& A. Shelton, Eds., pp. 40-67. Oxford: Clarendon Press.

Gell, A., 1998. Art and agency: An anthropological theory. Oxford: Oxford University Press.

Girard, R., 1958. Indios selváticos de la Amazonía peruana. México DF: Libro Max Editores.

Gombrich, E. H., 1999. El sentido del orden. Estudio sobre la psicología de las artes decorativas. Barcelona: Random House Mondadori.

GonzÁlez, P., 2006. Diaguitas a través de las Imágenes: Chamanismo y dualidad en el norte semiárido chileno. Revista de Arqueología Americana 24: 143-171. Organización de Estados Americanos: Instituto Panamericano de Geografía e Historia.

GonzÁlez, P., 2013. Arte y cultura Diaguita chilena: Simetría, simbolismo e identidad. Santiago: Ucayali Editores. 
Heath, C., 2002. Una ventana hacia el Infinito. El simbolismo de los diseños Shipibo-Conibo. En Una ventana hacia el infinito. Arte shipibo-conibo, P. Alayza \& F. Torres, Eds., pp. 45-50. Lima: Instituto Cultural Peruano Norteamericano.

Illius, B., 1991-1992. La "Gran Boa". Arte y cosmología de los Shipibo-Conibo. Scweizerische Amerikanisten-Gesellschaft Bulletin 55-56: 23-35.

Illius, B., 1994. La Gran Boa: Arte y cosmología de los Shipibo-Conibo. Amazonía Peruana 24 (12): 185-212.

INSTITUTO CULTURAL PERUANO NORTEAMERICANO 2002. Una Ventana hacia el infinito. Arte shipibo-conibo, P. Alayza \& F. Torres, Eds. Lima: Didi de Arteta s.A.

LAgrou, E., 2007. A fluidez da forma: Arte, alteridade e agencia em uma sociedade amazónica (Kaxinawa, Acre). Rio de Janeiro: Topbooks.

Lathrap, D., 1970. The upper Amazon. London: Thames \& Hudson.

LeVi-strauss, C., 1992 [1955]. Tristes Trópicos. Barcelona: Paidós.

Morales Chocano, D., 2002. Los ancestros del grupo cultural Shipibo-Conibo del Ucayali central en la Amazonía peruana. En Una ventana hacia el infinito. Arte shipibo-conibo, P. Alayza \& F. Torres, Eds., pp. 29-33. Lima: Instituto Cultural Peruano Norteamericano.

Morales Chocano, D., 2011. La arqueología en la Amazonía peruana y sus relaciones con el área andina. En Por dónde hay soplo, J. P. Chaumeil, O. Espinosa de Rivero \& M. Cornejo, Eds., pp. 137160. Lima: IFEA-PUCP.

PIAGET, J., 1970. Structuralism, trans. New York: Harper \& Row.

Preucel, R., 2006. Archaeological semiotics. Oxford: Blackwell Publishing.

Raymond, J. S.; W. De Boer y P. Roe, 1975. Cumancaya: A peruvian ceramic tradition. Occasional Papers 2. Calgary, Alberta: Department of Archaeology, University of Calgary.

Reichel-Dolmatoff, G., 1978. Beyond the milky way: Hallucinatory imagery of the Tukano Indians. California: UCLA Latin American Center Publications.
Reichel-Dolmatoff, G., 1985. Aspectos chamanísticos y neurofisiológicos del arte indígena. En Estudios en arte rupestre, Museo Chileno de Arte Precolombino, Ed., pp. 291-307. Santiago: Museo Chileno de Arte Precolombino.

Riviere, P., 1994. Myth and Material Culture: Some symbolic interrelations. En Forms, of symbolic action, C. Spencer, Ed., pp. 151-166. Seattle: University of Washington Press.

RoE, P., 1982. The cosmic zygote. Cosmology in the Amazon basin. New Brunswick: Rutgers University Press.

Strathern, A., 1988. The gender of the gift. Berkeley: University of California Press.

TAYLOR, A., 2008. Arte y mito en las culturas amazónicas. Universidad Pompeu Fabra. Centre Investigador en Art Primitiv i Primitivisme. Jornada Arte y Miti en las culturas primitivas. Conferencia $10 \mathrm{de}$ marzo de 2008, Barcelona. [online] pp.1-16.

http://www.upf.edu/ciap/_pdf/Conference_Taylor_Amazonas_peq. $\mathrm{pd}>$ [Citado 10-08-15]

Troncoso, A., 2005. El plato zoomorfo-antropomorfo diaguita: Una hipótesis interpretativa. Werken 6:113-124. Santiago: Universidad Internacional SEK.

Valenzuela, P. \& A. Valera, 2005. Koshi shinanya ainbo. El testimonio de una mujer shipiba. Lima: Universidad Nacional Mayor de San Marcos.

Viveiros de Castro, E., 1998. Cosmological deixis and amerindian perspectivism. The Journal of the Royal Anthropological Institute 4 (3): 469-488.

WASHBURN, D., 1977. A symmetry analysis of upper Gila area ceramic design. Papers of the Peabody Museum of Archaeology and Ethnology. Vol. 68. Cambridge: Harvard University.

Washburn, D. \& D. Crowe, 1988. Symmetries of culture. Theory and practice of plain pattern analysis. Seattle: University of Washington Press. 